\title{
Worker Flows and Job Flows: A Quantitative Investigation*
}

\author{
Shigeru Fujita ${ }^{\dagger}$ and Makoto Nakajima
}

March 31, 2009

\begin{abstract}
This paper studies cyclical properties of worker flows and job flows simultaneously in a multiple-worker version of the seach/matching model where firms decide how many workers they hire or shed under the presence of idiosyncratic and aggregate uncertainties. Wages are determined by intra-firm bargaining of Stole and Zwiebel (1996a,b). Our calibration incorporates micro- and macro-level evidence on worker and job flows as much as possible. We then show that the dynamic stochastic equilibrium of the model successfully replicates important cyclical features of worker flows and job flows. In particular, the model correctly predicts that hires from unemployment move countercyclically while the job creation rate move procyclically. We also find that the model fully accounts for volatilities of unemployment and vacancies when the outside option parameter is at $80 \%$ of aggregate labor productivity. We also show that the model successfully generates the strong negative relationship between unemployment and vacancies, i.e., the Beveridge curve, which the standard matching model with the endogenous separation decision fails to replicate.
\end{abstract}

JEL Classification: E24, E32, J63, J64

Keywords: Job flows, worker flows, search and matching, business cycles, unemployment, vacancies

${ }^{*}$ Incomplete draft. We would like to thank John Haltiwanger for useful discussions. Views expressed in this paper are those of ours and do not necessarily reflect the views of the Federal Reserve Bank of Philadelphia or the Federal Reserve System.

${ }^{\dagger}$ Research Department, Federal Reserve Bank of Philadelphia. Ten Independence Mall, Philadelphia, PA 19106. E-mail: shigeru.fujita@phil.frb.org.

${ }^{\ddagger}$ Research Department, Federal Reserve Bank of Philadelphia. Ten Independence Mall, Philadelphia, PA 19106. E-mail: makoto.nakajima@gmail.com. 


\section{Introduction}

This paper studies the quantitative properties of the multiple-worker version of the matching model. Our model features heterogeneous establishments which decide how many workers they hire or shed under the presence of idiosyncratic and aggregate uncertainties. In contrast to the existing papers, we solve for the stochastic dynamic equilibrium of the model and thus are able to assess its business cycle properties quantitatively. We use this model to explore the differences in the cyclicality of worker flows and job flows. We also study its capability of resolving the labor-market volatility puzzle by Shimer (2005).

Empirically, worker flows and job flows behave differently over the business cycles. It is well known that gross worker flows between unemployment and employment are countercyclical. ${ }^{1}$ The behavior of job flows is quite different from the behavior of worker flows. Specifically, job destruction is countercyclical whereas job creation is procyclical. ${ }^{2}$ However, there has been no attempt reconciling the differences in the literature. In the canonical model of labor search/matching a worker-firm match that operates linear technology is the unit of analysis. Empirically, however, job flows are measured from establishment-level employment observations, and thus the multiple-worker-firm environment is much more suitable for analyzing job flows. Furthermore, we can also keep track of labor market transitions of workers as well. Apart from reconciling the differences in the cyclicality of job flows and worker flows, there is a growing interest in the literature as to whether the multiple-worker version of the matching model is better able to resolving the volatility puzzle. Before discussing this paper's contributions, we first discuss more closely the relations of our paper to the previous literature.

Although the quantitative properties of the search/mathing models have been explored since 90s in various ways, it is Shimer (2005) who has spurred intense discussions on the model's quantitative capabilities. ${ }^{3}$ He shows that the textbook search/matching model grossly underpredicts volatilities of labor market variables. Since Shimer (2005), there have been many attempts to resolve this puzzle and a popular resolution is proposed by Hagedorn and Manovskii (2008), who

\footnotetext{
${ }^{1}$ Here we are talking about gross flows of workers. The recent literature focuses its interests on the cyclicality of the separation rate and the job finding rate. We will also look at the cyclicality of the transition rates. See the empirical features of worker flows, see, for example, Fujita and Ramey $(2006,2009)$ and references therein.

${ }^{2}$ See, for example, Davis, Haltiwanger and Schuh (1996), and Faberman (2006)). The evidence in the former work is limited to the manufacturing sector. The latter study shows that the same cyclical pattern holds for the entire economy.

${ }^{3}$ See Mortensen and Pissarides (1994), Merz (1995), Andolfatto (1996) and Den Haan, Ramey and Watson (2000) for earlier attempts.
} 
show that calibrating the model to match the profit rate of the firm makes it possible for the model to generate volatilities comparable to the empirical counterparts. This resolution based on an alternative calibration, however, is not always accepted by researchers. That is because the calibration implies the surplus enjoyed by the employment relationship is tiny (e.g., Mortensen and Nagypál (2007)).

A recent paper by Elsby and Michaels (2008) develops a multiple-worker version of the matching model where production technology exhibits decreasing returns to scale and firms make endogenous hiring and separation decisions under the presence of the search cost. They adopt the intra-firm bargaining framework by Stole and Zwiebel (1996a,b) to determine wages, which naturally generalizes Nash bargaining often used in the standard model. They emphasize the feature that downward sloping labor demand makes the surplus size of each match endogenous in this environment and argue that the model does a better job of magnifying the shock. The idea is that even though the level of marginal surplus is small, the average surplus can be quite large. However, their result is based on comparative statics under several restrictive assumptions. Moreover, they pay attention to neither cross-sectional implications of the model nor the difference between job flows and worker flows. ${ }^{4}$ Another recent paper by Cooper, Haltiwanger and Willis (2007) considers a similar environment and they do examine quantitative properties including aggregate dynamics as well as cross-sectional implications. They argue that the model does not suffer from the volatility puzzle. However, there are some important limitations in their analysis. First, wages are derived under the assumption that firms make a take-it-or-leave-it offer, implying that employed workers obtain zero surplus. Further, the important parameters are estimated to match the volatilities of unemployment and vacancies and thus it is unclear whether their result arise from the model's internal magnification mechanism or not.

This paper is also related to the long-standing literature on aggregate implications of the economy with a large number of heterogeneous establishments. We do not attempt to provide the exhaustive review of this literature. We instead focus on the recent papers most relevant for our paper. ${ }^{5}$ A paper by Campbell and Fisher (2000) is interested in the effects of hiring

\footnotetext{
${ }^{4}$ Acemoglu and Hawkins (2006) also develop a similar model and examine its implications for the volatility puzzle. However, their model assumes exogenous separations and they also consider only the steady-state comparative statics. Other papers that consider the multiple-worker-firm setting include Smith (1999), Cahuc and Wasmer (2001), and Cahuc, Marque and Wasmer (2008). But they assume exogenous separation and focus on analytical properties of the model. Yashiv (2006), Rotemberg (2006), and Krause and Lubik (2007) examine quantitative properties of the large-firm model, but again, exogenous separation is assumed.

${ }^{5}$ Important earlier contributions in this area can be found in the references of the papers discussed in this
} 
and firing costs on the dynamics of job creation and destruction rates. They, however, assume the competitive labor market so that there is no unemployment in their model. Further, the aggregate uncertainty takes the form of shocks to the aggregate wage rate that is exogenous to the model. Veracierto (2008) studies a similar environment but solves for the full stochastic general equilibrium in which all prices are endogenous. However, he focuses on the effects of firing taxes and again assumes the competitive labor market, so that no unemployment exists.

In summary, none of the existing papers attempts to match the behavior of both worker flows and job flows simultaneously. As mentioned above, the recent search/matching literature mostly focuses on worker transition rates whereas the literature on heterogeneous establishments studies job flows. We take a first step to integrate the two branches of the literature. In addition, we explore the model's ability to solve the volatility puzzle. In contrast to Elsby and Michaels (2008), we solve for the full dynamic stochastic equilibrium under a more general environment. We also make significant steps forward from Cooper, Haltiwanger and Willis's work.

Our model is derived from the one developed by Elsby and Michaels (2008). Our model, however, differs from theirs in two important ways. First, we allow for exogenous worker turnover, which play a critical role in our quantitative exercises. Second, we introduce the "firing cost" which is incurred when the firm endogenously sheds its workers. We calibrate the model at weekly frequency and then construct our measures of job flows and worker flows following the same procedure used by the BLS.

We show that the dynamic stochastic equilibrium of the model successfully replicates important cyclical features of worker flows and job flows. In particular, the model correctly predicts that hires from unemployment move countercyclically while job creation move procyclically. An important assumption to achieve this result is that workers separated due to endogenous job destruction go to the unemployment pool. This creates countercyclical job destruction as well as the worker flow into unemployment. When the negative aggregate shock hits the economy, the separation rate into unemployment increases while the job finding rate drops, as is the case in the standard search/matching models. The hiring flow from the unemployment pool rises as a result of increasing unemployment in the face of the negative shock.

However, an important observation to make is that the flow into unemployment takes up less than one third of establishment-level total separations. We assume that the remaining part of separations occur exogenously. The hiring flow associated with these exogenously separated workers moves procyclically because in this case, the movement of the job finding rate is the paragraph. 
only factor affecting the hiring flow. Given the presence of the large procyclical hiring flow, job creation, which counts all hiring flows, becomes procyclical.

We also find that the model fully accounts for volatilities of all variables considered even when the outside benefit parameter is around $80 \%$ of average labor productivity, which is much smaller than the value 95\% that is needed in Hagedorn and Manovskii (2008). Elsby and Michaels (2008) also show stronger magnification of the shock in their comparative static exercise. However, impulse response functions from our model reveal that the dynamic stochastic equilibrium implies large deviations from the steady state at least in the short run and that magnification of the shock largely come from such deviations. We also find that the model generates strong negative correlation between unemployment and vacancies. This is important because the standard search/matching model is known to be unable to this very robust empirical phenomenon.

In the next section, we review the business cycle facts about job flows and worker flows. Section 3 lays out the model and Section 4 provides some useful characterizations of the model. In Section 5, we put a great deal of an effort in calibrating the model as tightly as possible. We refer to the employment growth distribution as well as mean levels of job flows and worker transition rates. Section 6 gives a brief description of the computational method used to solve for the dynamics of the model. The details on the algorithm is given in Appendix A.3. Section 7 discusses the main results of this paper and also point out some problems of the model. We then conduct the sensitivity analysis in Section 8 with respect to three alternative calibrations. We find that our main results are largely robust, although one of the alternative calibrations implies volatilities of unemployment and vacancies that are roughly one half of the observed volatilities due to the smaller outside option value. ${ }^{6}$ Having established that the model replicates key dynamic features of the data, Section 9 uses the model to ask several important questions (TBA). Section 10 concludes the paper by offering important future research avenues identified by our results.

\section{Facts}

\subsection{Definitions}

Job flows. First, let us review the definitions of the empirical data. The job flow series are measured from the Business Employment Dynamics (BED) data which is based on the adminis-

\footnotetext{
${ }^{6}$ Note that in all of our calibrations, there is no degree of freedom to set $b$. Each calibration internally determines a certain level of the outside option parameter relative to average productivity.
} 
trative records of the Quarterly Census of Employment and Wages (QCEW). The coverage of the QCEW is very broad, representing $98 \%$ of employment on nonfarm payrolls. The administrative records are linked across quarters to provide a longitudinal history for each establishment. The linkage process allows the tracking of net employment changes at the establishment level, which in turn allows the computation of net employment gains at opening and expanding establishments and net employment losses at closing and contracting establishments.

The measures of job flows are originally developed by Davis, Haltiwanger and Schuh (1996): job creation (destruction) is defined as the sum of net employment gains (losses) over all establishment that expand (contract) or start up (shut down) between the two sampling dates. Since we are interested in business cycle fluctuations of the series, we use the data that trace net employment changes over a quarterly period. Normalizing creation and destruction by the corresponding employment size yields rates of job creation and destruction, respectively. ${ }^{7}$ In this paper, we use the term "job flows" to represent "rates" unless otherwise specifically mentioned. Job flows series are one of the most widely used measures to gauge the "churning" of the economy from the perspective of firms. The sample period of the job flow series starts at $1992 \mathrm{Q} 3$ and ends at $2008 \mathrm{Q} 2 .^{8}$

Worker flows. Similar but different measures can be constructed based on the changes in the labor market status of workers. The Current Population Survey (CPS) surveys a large sample of individual U.S. workers each month, ascertaining whether they are employed and, if nonemployed, whether they engaged in active job search activities (i.e., unemployed) over the preceding month. It is the official survey that underlies the unemployment rate, the employment-population ratio, etc. While the CPS is a repeated cross-section data, one can use longitudinal component of the survey to obtain measures of worker flows. We use the series constructed by Fujita and Ramey (2006). ${ }^{9}$ Our analysis focuses on gross worker flows and transition rates between employment and unemployment, although in the calibration section, we also discuss transitions into the outof-the-labor-force pool. Gross worker flows based on the CPS come from comparison of the labor market status at each monthly survey. To be specific, transition rates between employment and

\footnotetext{
${ }^{7}$ More precisely, average employment between the beginning and the end of the quarter is used for normalization.

${ }^{8}$ Unfortunately, the series only go back to the early 90s. Longer time series are available for the manufacturing sector. In terms of their cyclicality, job flows for the entire economy and the manufacturing sector behave similarly over the overlapping sample period. However, levels of job flows and their volatilities are significantly different.

${ }^{9}$ See that paper for measurement problems present in the CPS worker flows series.
} 
unemployment are, respectively, measured by:

$$
\frac{E U_{t-k, t}}{E_{t-k}} \text { and } \frac{U E_{t-k, t}}{U_{t-k}}
$$

where $E U_{t-k, t}\left(U E_{t-k, t}\right)$ refers to the number of workers who switch their labor market status from "employed" ("unemployed") to "unemployed" ("employed") between week $t-k$ and $t$. The value of $k$ takes either 4 or 5 depending on the calender. We call the former the separation rate into unemployment while calling the latter the job finding rate. The numerators $E U_{t-k, t}$ and $U E_{t-k, t}$ are what we call worker flows.

\subsection{Measurement in the Search/Matching Models}

The literature has explored whether the search/matching model is able to replicate the business cycle features of the U.S. labor market. Because the model is silent about which data to refer to in evaluating the model's quantitative performance, some researchers have used job flows while others have considered worker transition rates. For example, Mortensen and Pissarides (1994), Cole and Rogerson (1999), and Den Haan, Ramey and Watson (2000) all evaluate the model's performance with respect to job flows. On the other hand, probably starting with Shimer (2005), the literature's focus has sifted toward fluctuations of worker transition rates, in particular, the job finding rate of unemployed workers.

However, as we will see, job flows and worker flows behave quite differently over the business cycle, meaning that the canonical models of labor search/matching are unable to explain both at the same time. Furthermore, it is misleading to evaluate the quantitative performance of the model that does not have a notion of "firm," particularly with respect to the data measured from firm's perspective.

\subsection{The Cyclicality of Worker and Job Flows}

Unimportance of entry and exit. First, consider Figure 1 where we plot the time series of job flow series in the private business sector. In the figure, we show not only the total rates of job creation and destruction but also their breakdowns into expansion, entry, contraction, and exit. The intention of this figure is to show unimportance of the extensive margins for the business cycle fluctuations of job flows. According to the data, roughly $75 \%$ of total job flows come from expansion or contraction of the existing establishments. More important, the cyclical fluctuations of total job flows are mostly accounted for by expansion or contraction. For instance, 


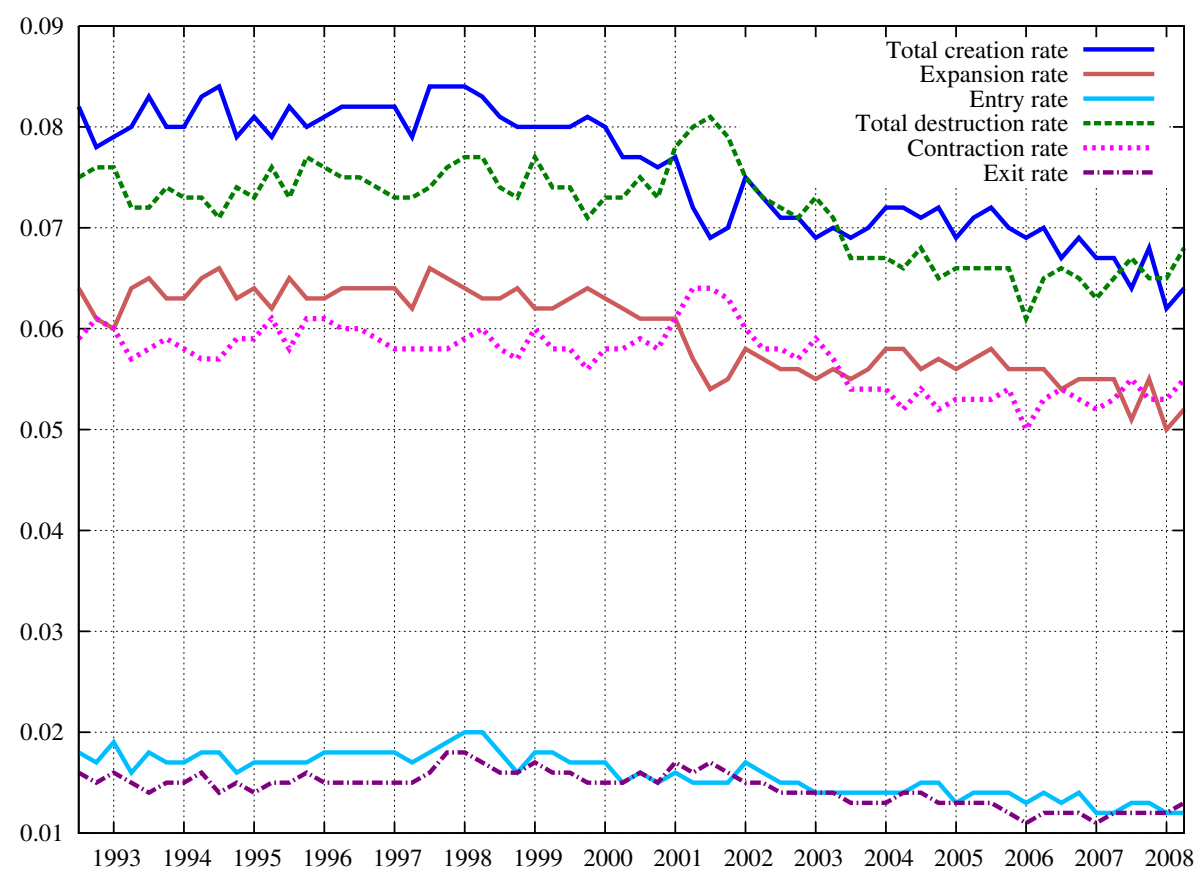

Figure 1: Job creation and destruction rates

Notes: The data are from BLS Business Employment Dynamics and cover the entire private business sector.

correlation between the total job creation (destruction) rate and the expansion (contraction) rate is 0.985 (0.976). This fact is important because our model developed in the next section does not feature extensive margins. The statistics below are thus calculated using the expansion rate and contraction rate. From here on, we use the terms "job creation rate" and "job destruction rate" to represent the expansion rate and contraction rate, respectively.

Business cycle statistics. Table 1 characterizes the cyclicality of job flows and worker flows using standard business cycle statistics. The original series are logged and then detrended by using the HP filter with smoothing parameter of 1600. As mentioned above, original worker flows and transition rates are monthly series. We render them quarterly by simple averaging so that we can examine their cyclicality on an equal footing with the job flow series. The labor productivity series is used as a cyclical indicator to judge each variable's volatility and cyclicality.

We can summarize the characteristics of the labor flows as follows. First, the separation rate into unemployment is countercyclical and the job finding rate is procyclical. The job find- 
ing rate is somewhat more volatile than the separation rate. ${ }^{10}$ Second, worker flows are both countercylical. Both the separation flow is somewhat more volatile than the hiring flow. The countercyclicality of separations into unemployment directly comes from the countercyclical separation rate. Hires from unemployment are countercyclical because the size of the unemployment pool increases rapidly during recessionary periods (due to the faster inflow from employment) which in turn raises hires even though the job finding rate declines. Fourth, the job destruction rate is countercylical and the job creation rate is procyclical. The job destruction rate is somewhat more volatile than the job creation rate. Finally, worker flows are more volatile than job flows.

Table 1 also present volatilities of the unemployment rate and vacancies. As is well known in the literature, these two variables are quite volatile when compared with volatility of labor productivity. Recent literature, since Shimer (2005), has paid a close attention to the model's capability of generating the large volatilities. Further, we can also see the well-known fact about the cyclicality of unemployment and vacancies (i.e., Beveridge curve). Whether or not or mode is account for the Beveridge curve relationship is important in that the standard search/matching model of Mortensen and Pissarides (1994) that features the endogenous separation decision fails to replicate this very robust empirical phenomenon.

\section{Model}

The model presented here is derived from the one developed by Elsby and Michaels (2008). Our model, however, differs from theirs in two important ways. First, we allow for exogenous worker turnover, which turns out to play a critical role in our quantitative exercises. Second, we introduce the "firing cost" which is incurred when a firm endogenously sheds its workers.

Time is discrete. There are two types of agents, firms and workers. Both are infinitely lived. The total measure of firms is normalized to one. The total measure of workers is denoted by $L$. The timing of events is summarized in Figure 2. Since we write down the model recursively, we drop time subscripts from all variables and follow the convention that primes and double-primes denote variables in the next period and the following period, respectively.

\footnotetext{
${ }^{10}$ Shimer (2007) and Hall (2005) argue that the separation rate into unemployment is roughly constant over the business cycle. Fujita and Ramey (2006, 2009), Fujita (forthcoming), Elsby, Michaels and Solon (2009), Canova, Lopez-Salido and Michelacci (2007), and Yashiv (2007) argue otherwise.
} 
Table 1: Empirical Facts on Job Flows and Worker Flows

\begin{tabular}{lccr}
\hline \hline & & Relative & Corr with \\
& SD & SD & labor prod. \\
\hline Worker flows & & & \\
Emp. to unemp. & 0.0575 & 7.587 & -0.579 \\
Unemp. to emp. & 0.0459 & 6.056 & -0.347 \\
\hline Transition rates & & & \\
$\quad$ Separation rate & 0.0639 & 8.431 & -0.579 \\
$\quad$ Job finding rate & 0.0692 & 9.130 & 0.415 \\
\hline Job flows & & & \\
$\quad$ Creation rate & 0.0272 & 4.512 & 0.293 \\
$\quad$ Destruction rate & 0.0310 & 5.143 & -0.455 \\
\hline Stocks & & & \\
$\quad$ Unemployment rate & 0.0996 & 13.148 & -0.448 \\
$\quad$ Vacancies & 0.1296 & 17.097 & 0.572 \\
\hline
\end{tabular}

Notes: All series are logged and HP filtered with smoothing parameter of 1600 . The second column gives the volatility of each variable relative to that of labor productivity. The labor productivity series is constructed by dividing real GDP by the number employed reported in the CPS. The sample period for worker flows, transition rates, unemployment and vacancies is 1976Q1 through 2005Q4. Original monthly data are converted into quarterly by time averaging. The sample period for job flows is 1992Q3 through 2008Q2. The sample period for labor productivity differs depending on the sample period of each variable.

\subsection{Firm}

At the beginning of each period, a firm is characterized by $(x, d, n)$. The variable $x$ represents idiosyncratic productivity of a firm. The variable $d$ is the proportion of workers leaving the firm voluntarily before the firm makes its employment decision. In other words, $d$ represents the size of exogenous separations. The variable $n$ is the number of workers employed at the firm. Let $m$ be the type distribution of firms. In addition, firms are affected by the aggregate productivity shock $z$. The aggregate state of the world is represented by $(z, m)$. We use $G_{z}\left(z^{\prime} \mid z\right), G_{x}\left(x^{\prime} \mid x\right)$, and $G_{d}\left(d^{\prime} \mid d\right)$ to represent the stochastic process of $z, x$, and $d$, respectively.

In each period, a firm (i) may lose part of its workers according to realization of the exogenous separation shock $d$, (ii) adjusts the number of workers (either by hiring or shedding), (iii) negotiates the wage with its workers, and (vi) produces and pays the negotiated wage to the workers.

In the first stage, $d n$ workers leave the firm exogenously. The variable $d$ could be zero in which case no worker leaves the firm. Note that it is natural to assume that all firms lose workers at 


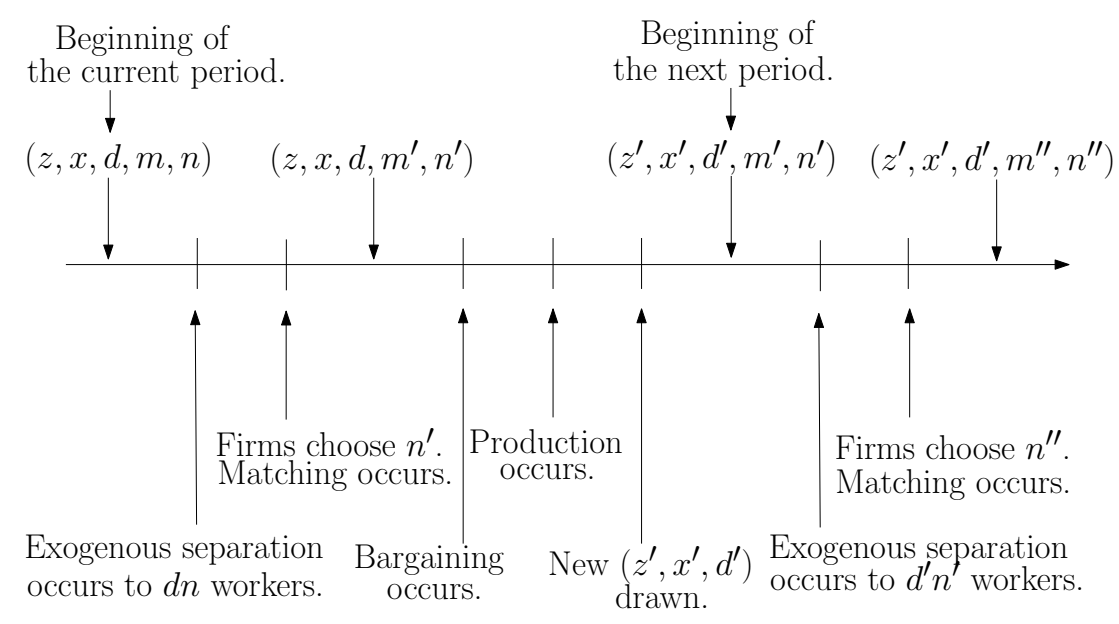

\section{Figure 2: Timing of events}

a constant rate every period, which is nested in our specification. However, as will be discussed in Section 5, our specification gives us a flexibility of matching a certain cross-sectional feature of the data. Since those workers are considered to leave the firm voluntarily, we assume that exogenous separations impose no direct costs on the firms.

In the next stage, the firm adjusts the size of employment. We assume that when the firminitiated reduction of its employment size occurs, firm incurs the "firing cost" $\tau$ per worker. Recall that the marginal cost of exogenous separation is zero. Therefore, with $\tau>0$, a firm, which desires to reduce its size of employment, does not necessarily appeal to endogenous reduction of its size. Instead, it may choose to let its size shrink through exogenous worker turnover. Hiring workers requires the firm to post vacancies. As is standard in the search/matching literature, it is assumed that it incurs the flow vacancy posting cost $\kappa$ for each vacancy posted. Each vacancy is filled with the job filling probability $q(z, m)$, which will be endogenized later. Because of the law of large numbers, the cost of hiring a worker turns out to be deterministic and $\frac{\kappa}{q(z, m)}$. Observe that the firm can always hire the exact number of workers it is willing to hire by taking into account the job filling probability.

In the production stage, following production technology is available to all firms:

$$
y=z x F\left(n^{\prime}\right)
$$

where $F^{\prime}>0$ and $F^{\prime \prime}<0$. A prime is attached to the employment size $n$ due to our timing assumption. The negotiated wage is a function of both aggregate and individual states and thus is expressed as $w\left(z, x, d, m^{\prime}, n^{\prime}\right)$. The expected present discount value of the firm before the 
employment decision, $\Pi(z, x, d, m, n)$, can be represented as follows:

$$
\begin{aligned}
& \Pi(z, x, d, m, n)=\max _{n^{\prime} \geq 0}\left\{z x F\left(n^{\prime}\right)-w\left(z, x, d, m^{\prime}, n^{\prime}\right) n^{\prime}-\frac{\kappa}{q(z, m)} \max \left(n^{\prime}-(1-d) n, 0\right)\right. \\
& \left.-\tau \max \left((1-d) n-n^{\prime}, 0\right)+\beta \iiint \Pi\left(z^{\prime}, x^{\prime}, d^{\prime}, m^{\prime}, n^{\prime}\right) d G_{d}\left(d^{\prime} \mid d\right) d G_{x}\left(x^{\prime} \mid x\right) d G_{z}\left(z^{\prime} \mid z\right)\right\},
\end{aligned}
$$

where $m^{\prime}=\Phi_{m}(z, m)$ is a law of motion of the type distribution of firms. The terms $\frac{\kappa}{q(z, m)} \max \left(n^{\prime}-\right.$ $(1-d) n, 0)$ and $\tau \max \left((1-d) n-n^{\prime}, 0\right)$ capture the hiring and firing costs, respectively. Naturally, these costs are asymmetric. Notice also that workers at the same firm obtain the same wage $w\left(z, x, d, m^{\prime}, n^{\prime}\right)$. The Bellman equation above yields the optimal decision rule of the firm $n^{\prime}=\phi_{n}(z, x, d, m, n)$.

\subsection{Worker}

Workers are engaged in one of the two activities, producing or searching for a job. When working at the firm characterized by $\left(x, d, n^{\prime}\right)$ under the aggregate states $z$ and $m^{\prime}$, he receives the bargained wage $w\left(z, x, d, m^{\prime}, n^{\prime}\right)$. In the following period, with probability $d^{\prime}$, the worker leaves the firm exogenously. If he does not leave the firm in the next period, he can either stay with the same firm or be subject to the risk of endogenous separation. After separating from the firm, whether endogenously or endogenously, the worker starts looking for the next job.

While the worker is looking for a job, he obtains the flow value $b$ per period. With probability $f\left(z^{\prime}, m^{\prime}\right)$, which we will characterize later, the worker will find a job and become employed in the next period. Let $W_{e}\left(z, x, d, m^{\prime}, n^{\prime}\right)$ and $W_{s}\left(z, m^{\prime}\right)$ be the values of being employed and looking for a job, respectively, the two values can be represented using the following Bellman equations:

$$
\begin{aligned}
& W_{e}\left(z, x, d, m^{\prime}, n^{\prime}\right)=w\left(z, x, d, m^{\prime}, n^{\prime}\right) \\
& +\beta \iiint\left(d^{\prime}+\left(1-d^{\prime}\right) \mathcal{I}_{n^{\prime \prime}<\left(1-d^{\prime}\right) n^{\prime}} \frac{\left(1-d^{\prime}\right) n^{\prime}-n^{\prime \prime}}{\left(1-d^{\prime}\right) n^{\prime}}\right) W_{s}\left(z^{\prime}, m^{\prime \prime}\right) \\
& +\left(1-d^{\prime}\right)\left(\mathcal{I}_{n^{\prime \prime}>\left(1-d^{\prime}\right) n^{\prime}}+\mathcal{I}_{n^{\prime \prime}=\left(1-d^{\prime}\right) n^{\prime}}+\mathcal{I}_{n^{\prime \prime}<\left(1-d^{\prime}\right) n^{\prime}} \frac{n^{\prime \prime}}{\left(1-d^{\prime}\right) n^{\prime}}\right) W_{e}\left(z^{\prime}, x^{\prime}, d^{\prime}, m^{\prime \prime}, n^{\prime \prime}\right) \\
& \quad d G_{d}\left(d^{\prime} \mid d\right) d G_{x}\left(x^{\prime} \mid x\right) d G_{z}\left(z^{\prime} \mid z\right), \\
& W_{s}\left(z, m^{\prime}\right)=b+\beta \int\left(1-f\left(z^{\prime}, m^{\prime}\right)\right) W_{s}\left(z^{\prime}, m^{\prime \prime}\right) d G_{z}\left(z^{\prime} \mid z\right) \\
& \quad+\beta \iint f\left(z^{\prime}, m^{\prime}\right) W_{e}\left(z^{\prime}, x^{\prime}, d^{\prime}, m^{\prime \prime}, n^{\prime \prime}\right) d G_{f}\left(x^{\prime}, d^{\prime}, n^{\prime \prime}\right) d G_{z}\left(z^{\prime} \mid z\right),
\end{aligned}
$$


where $m^{\prime \prime}=\Phi_{m}\left(z^{\prime}, m^{\prime}\right), n^{\prime \prime}=\phi_{n}\left(z^{\prime}, x^{\prime}, d^{\prime}, m^{\prime}, n^{\prime}\right)$, and $G_{f}\left(x^{\prime}, d^{\prime}, n^{\prime \prime}\right)$ represents the type distribution of hiring firms. $\mathcal{I}$ is an indicator function which takes the value 1 if the logical expression attached to it is true and takes the value zero otherwise. In (3), the term multiplied by $W_{s}\left(z^{\prime}, m^{\prime \prime}\right)$ represents the case where the worker leaves the firm, and the term multiplied by $W_{e}\left(z^{\prime}, x^{\prime}, d^{\prime}, m^{\prime \prime}, n^{\prime \prime}\right)$ represents the case where the worker stays with the firm.

\subsection{Bargaining}

Since production technology exhibits diminishing returns and the firm can employ multiple workers, bargaining is not as trivial as in the standard setting which features bargaining between one worker and one firm. We adopt the bargaining solution proposed by Stole and Zwiebel (1996a,b), which generalizes the Nash bargaining solution to a setting with the downward-sloping labor demand curve. Stole and Zwiebel present a game where bargained wage is the same as the outcome of simple Nash bargaining over the marginal surplus.

The bargaining outcome implied by the game of Stole and Zwiebel (1996a,b) can be formulated as follows. Remember that, since firms finished adjusting the number of workers hired $\left(n^{\prime}\right)$ at the timing of negotiation each period, the hiring costs are sunk in the negotiation. The marginal surplus of a firm, which we denote $J\left(z, x, d, m^{\prime}, n^{\prime}\right)$, takes the following form:

$$
J\left(z, x, d, m^{\prime}, n^{\prime}\right)=z x F^{\prime}\left(n^{\prime}\right)-w\left(z, x, d, m^{\prime}, n^{\prime}\right)-w_{n}\left(z, x, d, m^{\prime}, n^{\prime}\right) n^{\prime}+\beta D\left(z, x, d, m^{\prime}, n^{\prime}\right)
$$

where

$$
D\left(z, x, d, n^{\prime}, m^{\prime}\right)=\iiint \Pi_{n}\left(z^{\prime}, x^{\prime}, d^{\prime}, m^{\prime}, n^{\prime}\right) d G_{d}\left(d^{\prime} \mid d\right) d G_{x}\left(x^{\prime} \mid x\right) d G_{z}\left(z^{\prime} \mid z\right)
$$

is the expected marginal profit of the firm. Wages are the outcome of a Nash bargaining between a firm and its workers over the marginal surplus. If we denote the bargaining power parameter of

the workers as $\eta$, the bargained wage $w\left(z, x, d, m^{\prime}, n^{\prime}\right)$ is implicitly characterized by the following wage equation:

$$
(1-\eta)\left[W_{e}\left(z, x, d, m^{\prime}, n^{\prime}\right)-W_{s}\left(z, m^{\prime}\right)\right]=\eta\left[J\left(z, x, d, m^{\prime}, n^{\prime}\right)+\tau\right]
$$

Notice that the marginal firing cost $\tau$ enters the firm's side. This is because of the existence of the firing cost.

\subsection{Matching and Separation}

Matching technology is characterized by an aggregate matching function $M=M(S, V)$, where $M$ is the number of new matched created, $S$ is the number of workers searching for a job, and 
$V$ is the number of vacancies posted. Notice that, when matching occurs, the type distribution of firms is represented by $m$. We can compute $S$ from $m$ and the total number of workers $L$ as follows:

$$
S(m)=L-\int n d m
$$

When firms make decision about hiring/firing, firms do not know $V$ a priori. Since knowing $V$ is crucial in forming expectation about the job filling rate $q(z, m)$, firms form expectation about $V$. We denote $V=\Phi_{V}(z, m)$ as the forecasting function used by all agents in the model economy to predict the number of vacancies posted when the aggregate state is $(z, m)$. In equilibrium, expected $V$ has to coincide with the realized $V$, which we denote $\widetilde{V}$. Using the optimal hiring/firing policy of firms, $\widetilde{V}$ can be computed as follows:

$$
\widetilde{V}=\frac{\int \max \left(\phi_{n}(z, x, d, m, n)-(1-d) n, 0\right) d m}{q(z, m)}
$$

Notice that max operator is used to count only the number of new jobs that firms create. Also notice that, in order to predict $q(z, m)$, firms need to predict $V$.

Now, the expected new matches created can be defined as follows:

$$
M(z, m)=M\left(S(m), \Phi_{V}(z, m)\right)
$$

The expected job-finding probability $f(z, m)$ and the expected vacancy-filling probability $q(z, m)$ can be represented as follows:

$$
\begin{aligned}
& f(z, m)=\frac{M(z, m)}{S(m)} \\
& q(z, m)=\frac{M(z, m)}{\Phi_{V}(z, m)}
\end{aligned}
$$

Aggregate hiring under that aggregate state $(z, m)$ can be computed by:

$$
\int \max \left(\phi_{n}(z, x, d, m, n)-(1-d) n, 0\right) d m
$$

Aggregate separation due to exogenous separation can be computed by:

$$
\int d n d m
$$

Aggregate separation due to endogenous separation can be computed by:

$$
\int \max \left((1-d) n-\phi_{n}(z, x, d, m, n), 0\right) d m
$$

Consequently, aggregate total separation is:

$$
\int d n+\max \left((1-d) n-\phi_{n}(z, x, d, m, n), 0\right) d m
$$




\subsection{Equilibrium}

\section{Definition 1 (Stationary equilibrium)}

A stationary equilibrium of the model economy consists of the value functions, $\Pi(z, x, d, m, n)$, $D\left(z, x, d, m^{\prime}, n^{\prime}\right), W_{e}\left(z, x, d, m^{\prime}, n^{\prime}\right), W_{s}\left(z, m^{\prime}\right)$, optimal decision rule $\phi_{n}(z, x, d, m, n)$, wage function $w\left(z, x, d, m^{\prime}, n^{\prime}\right)$, forecasting functions of the employment in the next period $\Phi_{m}(z, m)$ and number of vacancies $\Phi_{V}(z, m)$, such that:

1. Given forecasting functions and wage function, firms choose $\phi_{n}(z, x, d, m, n)$ optimally, and $\Pi(z, x, d, m, n)$ is the resulting value function, solving (2).

2. $D\left(z, x, d, m^{\prime}, n^{\prime}\right)$ is consistent with the optimal decision rule $\phi_{n}(z, x, d, m, n)$.

3. Given forecasting functions, wage function, and firms' optimal decision rules, $W_{e}\left(z, x, d, m^{\prime}, n^{\prime}\right)$ and $W_{s}\left(z, m^{\prime}\right)$ solve the Bellman equations (3) and (4), respectively.

4. $w\left(z, x, d, m^{\prime}, n^{\prime}\right)$ is the Nash bargaining solution characterized by (7).

5. Forecasting function $\Phi_{m}(z, m)$ is consistent with the stochastic process of $x$ and the optimal decision rule $\phi_{n}(z, x, d, m, n)$.

6. Forecasting function $\Phi_{V}(z, m)$ is consistent with the actual number of vacancies, which is implied by firms' optimal decision rule.

\section{Characterization}

\subsection{Optimal Hiring/Firing Rules}

First we characterize the optimal decision rule of firms and then the bargaining outcome. Even though the model does not have a simple analytical solution like in the case of Elsby and Michaels (2008), the characterization greatly helps us solving the model numerically.

Let us start form the firm's problem. Using the recursive formulation of firms' expected present discount value of profits (5), firm's optimal decision is characterized by the following first order conditions with respect to $n^{\prime}$ :

$$
\begin{aligned}
z x F^{\prime}\left(n^{\prime}\right)-w\left(z, x, d, m^{\prime}, n^{\prime}\right) & -w_{n}\left(z, x, d, m^{\prime}, n^{\prime}\right) n^{\prime} \\
& -\frac{\kappa}{q(z, m)} \mathcal{I}_{n^{\prime}>(1-d) n}+\tau \mathcal{I}_{n^{\prime}<(1-d) n}+\beta D\left(z, x, d, m^{\prime}, n^{\prime}\right)=0
\end{aligned}
$$


$\mathcal{I}$ is an indicator function which takes the value 1 if the logical expression attached to it is true and takes the value zero otherwise. The indicator function is needed because the marginal cost of adjusting $n^{\prime}$ is the hiring cost if the firm is increasing employment after the exogenous separation occurs $\left(n^{\prime}>(1-d) n\right)$, zero if the firm is not changing the employment $\left(n^{\prime}=(1-d) n\right)$, and the firing $\operatorname{cost} \tau$ when the firm is shedding workers in addition to those who left due to exogenous separation $\left(n^{\prime}<(1-d) n\right)$.

The first order condition (17) is helpful in characterizing the optimal decision of the firms. First, notice that the only term which includes the current $n$ is the marginal adjustment costs of employment $\frac{\kappa}{q(z, m)} \mathcal{I}_{n^{\prime}>(1-d) n}$ and $\tau \mathcal{I}_{n^{\prime}<(1-d) n}$. This implies that the solution to the first order condition is affected by the current $n$ only through the marginal adjustment costs of employment. Since both $\frac{\kappa}{q(z, m)}$ and $\tau$ are positive, the left hand side of the first order condition in case $n^{\prime}>(1-d) n$ can be obtained by shifting down the left hand side for $n^{\prime}=(1-d) n$ downward, as in Figure 3. In case $n^{\prime}<(1-d) n$, the left hand side of the first order condition is obtained by shifting the one for $n^{\prime}=(1-d) n$ upward, again as in Figure 3. The solutions to the first order condition corresponding to the cases $n^{\prime}>(1-d) n$ and $n^{\prime}<(1-d) n$ are $\underline{n}^{*}$ and $\bar{n}^{*}$, respectively. Using $\underline{n}^{*}$ and $\bar{n}^{*}$, we can characterize the optimal decision rule $\phi_{n}(z, x, d, m, n)$ as follows:

where $\bar{n}^{*}$ and $\underline{n}^{*}$ are respectively characterized by:

$$
\begin{aligned}
& z x F^{\prime}\left(\bar{n}^{*}\right)-w\left(z, x, d, m^{\prime}, \bar{n}^{*}\right)-w_{n}\left(z, x, d, m^{\prime}, \bar{n}^{*}\right) \bar{n}^{*}+\tau+\beta D\left(z, x, d, m^{\prime}, \bar{n}^{*}\right)=0 \\
& z x F^{\prime}\left(\underline{n}^{*}\right)-w\left(z, x, d, m^{\prime}, \underline{n}^{*}\right)-w_{n}\left(z, x, d, m^{\prime}, \underline{n}^{*}\right) \underline{n}^{*}-\frac{\kappa}{q(z, m)}+\beta D\left(z, x, d, m^{\prime}, \underline{n}^{*}\right)=0
\end{aligned}
$$

Figure 4 exhibits the optimal decision rule for a given $(z, x, d, m)$. The optimal decision rule is similar to an $(s, S)$ rule, with $\left[\underline{n}^{*}, \bar{n}^{*}\right]$ as the inactive region. When the current $n$ after exogenous separation $((1-d) n)$ is above $\bar{n}^{*}$, the firm reduces its employment down to $\bar{n}^{*}$. When $(1-d) n$ is below $\underline{n}^{*}$, the firm increases its employment up to $\underline{n}^{*}$. When $(1-d) n$ is in the inactive region, the firm lets its employment size decline with the exogenous separation only. When there is no exogenous separation (when $d$ is always zero), the diagonal line in Figure 4 becomes a 45 degree line and the optimal decision rule becomes the standard $(s, S)$ rule.

In order to compute the optimal decision rule, we need to have the wage function $w\left(z, x, d, m^{\prime}, n^{\prime}\right)$, and $D\left(z, x, d, m^{\prime}, n^{\prime}\right)$, which is firm's expected marginal value with respect to $n^{\prime}$. How can we compute $D\left(z, x, d, m^{\prime}, n^{\prime}\right)$ ? Using (6), the definition of $D\left(z, x, d, m^{\prime}, n^{\prime}\right)$, and the optimal decision rule that we just obtained, we can characterize the updating formula for $D\left(z, x, d, m^{\prime}, n^{\prime}\right)$ as follows: 


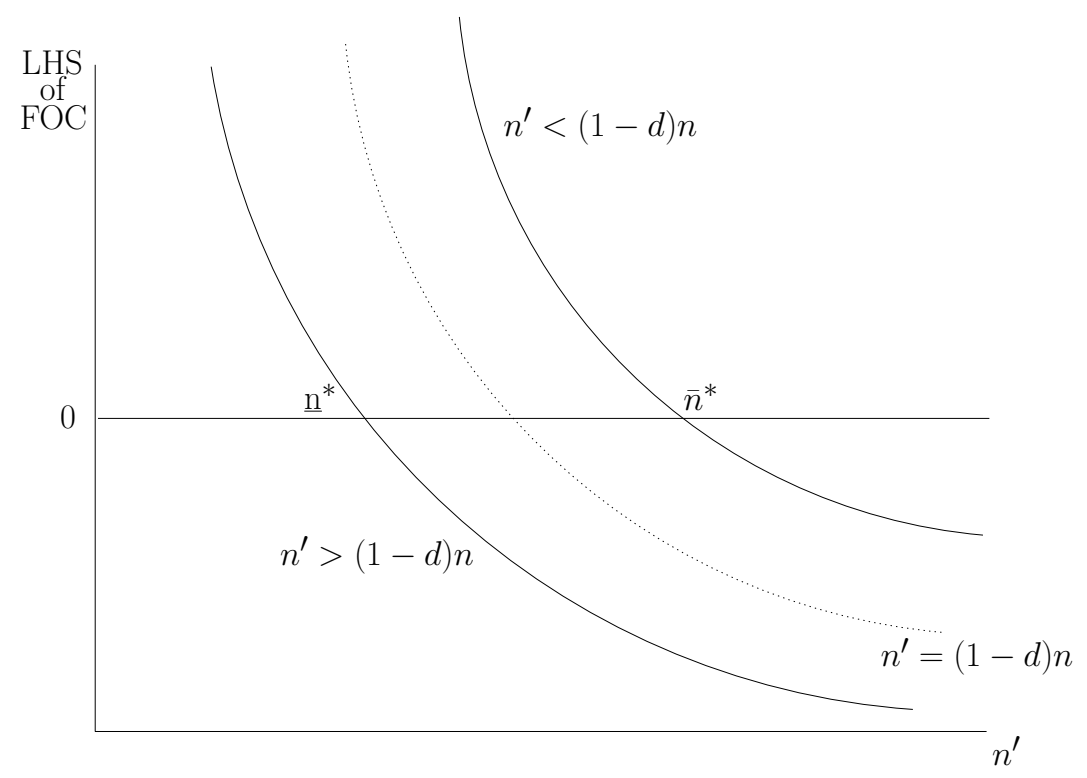

Figure 3: First Order Condition

$$
D\left(z, x, d, m^{\prime}, n^{\prime}\right)=\iiint \Pi_{n}\left(z^{\prime}, x^{\prime}, d^{\prime}, m^{\prime}, n^{\prime}\right) d G_{d}\left(d^{\prime} \mid d\right) d G_{x}\left(x^{\prime} \mid x\right) d G_{z}\left(z^{\prime} \mid z\right)
$$

where

$$
\begin{aligned}
& \Pi_{n}\left(z^{\prime}, x^{\prime}, d^{\prime}, m^{\prime}, n^{\prime}\right)=\left(1-d^{\prime}\right) \\
& \begin{cases}-\tau & \text { if } \widetilde{n}^{\prime}>\bar{n}^{*} \\
z^{\prime} x^{\prime} F^{\prime}\left(\widetilde{n}^{\prime}\right)-w\left(z^{\prime}, x^{\prime}, d^{\prime}, m^{\prime \prime}, \widetilde{n}^{\prime}\right)-w_{n}\left(z^{\prime}, x^{\prime}, d^{\prime}, m^{\prime \prime}, \widetilde{n}^{\prime}\right) \widetilde{n}^{\prime}+\beta D\left(z^{\prime}, x^{\prime}, d^{\prime}, m^{\prime \prime}, \widetilde{n}^{\prime}\right) & \text { if } \widetilde{n}^{\prime} \in\left[\underline{n}^{*}, \bar{n}^{*}\right] \\
\frac{\kappa}{q\left(z^{\prime}, m^{\prime}\right)} & \text { if } \widetilde{n}^{\prime}<\underline{n}^{*}\end{cases}
\end{aligned}
$$

and $m^{\prime \prime}=\Phi_{m}\left(z^{\prime}, m^{\prime}\right), \widetilde{n}^{\prime}=\left(1-d^{\prime}\right) n^{\prime}, \bar{n}^{*}$ and $\underline{n}^{*}$ are characterized by equations (18), (19), respectively, for $\left(z^{\prime}, x^{\prime}, d^{\prime}, m^{\prime}\right)$. For the steady state version of the model without exogenous separation and firing cost, Elsby and Michaels (2008) show that Equation (20) is a contraction mapping in $D$, and thus has a unique fixed point.

\subsection{Bargaining Outcome}

Combining (5), (3), (4) and (17) with the formula for the Nash bargaining solution (7), we can obtain the following differential equation which implicitly characterizes the bargaining outcome. 


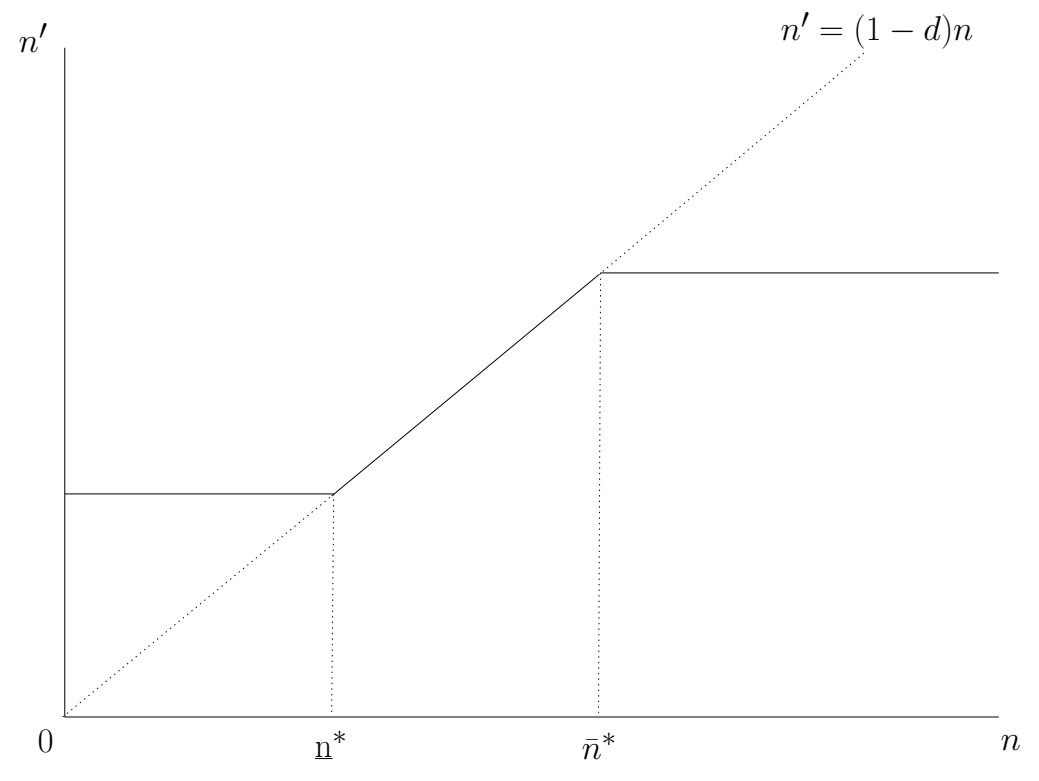

Figure 4: Optimal $n^{\prime}$

For the details of how to obtain the wage equation, see Appendix A.1. ${ }^{11}$

$$
\begin{aligned}
& w\left(z, x, d, m^{\prime}, n^{\prime}\right)=(1-\eta) b+\eta\left[z x F^{\prime}\left(n^{\prime}\right)-w_{n}\left(z, x, d, m^{\prime}, n^{\prime}\right) n^{\prime}\right. \\
& \left.+\tau\left(1-\beta+\beta \int d^{\prime} d G_{d}\left(d^{\prime} \mid d\right)\right)+\beta \int f\left(z^{\prime}, m^{\prime}\right)\left(\tau+\frac{\kappa}{q\left(z^{\prime}, m^{\prime}\right)}\right) d G_{z}\left(z^{\prime} \mid z\right)\right]
\end{aligned}
$$

If we further assume $F(n)=n^{\alpha}$, we can obtain the following closed form solution of the differential equation above.

$$
\begin{aligned}
& w\left(z, x, d, m^{\prime}, n^{\prime}\right)=(1-\eta) b+\eta\left[\frac{z x \alpha n^{\prime \alpha-1}}{1-\eta(1-\alpha)}\right. \\
&\left.+\tau\left(1-\beta+\beta \int d^{\prime} d G_{d}\left(d^{\prime} \mid d\right)\right)+\beta \int f\left(z^{\prime}, m^{\prime}\right)\left(\tau+\frac{\kappa}{q\left(z^{\prime}, m^{\prime}\right)}\right) d G_{z}\left(z^{\prime} \mid z\right)\right]
\end{aligned}
$$

For the details of how to obtain the wage equation, see Appendix A.2. Equation (22) corresponds to equation (10) of Elsby and Michaels (2008).

\section{Calibration}

This section discusses the benchmark calibration of the model. The model is calibrated at weekly frequency. We exert a great deal of effort to calibrate the model as tightly as possible. With

\footnotetext{
${ }^{11}$ Also see Proposition 1 of Elsby and Michaels (2008).
} 
respect to the parameters for which we do not have very tight identifying restrictions, we will conduct the sensitivity analysis in the next section.

\subsection{Functional Forms}

We assume that the matching function takes the Cobb-Douglas form:

$$
M=M(S, V)=\mu S^{\psi} V^{1-\psi}
$$

The production function for individual firms is assumed to take the simple functional form which exhibits decreasing returns to scale with $\alpha<1$ :

$$
y=z x F(n)=z x n^{\alpha} .
$$

Both the aggregate and idiosyncratic productivity shocks follow standard AR(1) processes:

$$
\begin{aligned}
& z^{\prime}=\rho_{z} z+\epsilon_{z}, \\
& x^{\prime}=\rho_{x} x+\epsilon_{x},
\end{aligned}
$$

where $\epsilon_{z} \sim N\left(0, \sigma_{z}^{2}\right)$, and $\epsilon_{x} \sim N\left(0, \sigma_{x}^{2}\right){ }^{12}$ The exogenous separation probability $d$ is chosen to follow the following process:

$$
d= \begin{cases}\widetilde{d} & \text { with probability } p_{d} \\ 0 & \text { with probability } 1-p_{d}\end{cases}
$$

where $p_{d}$ denotes the probability that exogenous separations occur at each firm. Conditional on the firm being hit by the shock, each worker faces the separation probability of $\widetilde{d}$. As we will see later in this section, this process gives us a flexibility of matching a certain feature of the employment growth distribution. ${ }^{13}$

\footnotetext{
${ }^{12}$ The search/matching literature, including Elsby and Michaels (2008) often uses the memoryless process for $x$. That is, with a certain probability, idiosyncratic productivity stays at the same level as in the previous period, and otherwise the new level is drawn. Adopting this process helps obtain an analytical solution while maintaining persistence of the idiosyncratic shock. However, the memoryless property does not appear consistent with evolution of establishment-level productivities.

${ }^{13} \mathrm{An}$ alternative is to assume $p_{d}=1$, so that all firms shed workers at the same exogenous rate. Our specification nests this alternative but the model is not able to match the feature with $p_{d}=1$.
} 


\subsection{Measurement of Labor Market Flows}

Measurement of worker flows and job flows plays an important role in our quantitative exercises. We need to address two important issues here.

First, job flows are measured from establishment-level net employment changes over a quarter as discussed in Section 2. Worker flows are measured from the changes in the labor market status over a monthly period. The difference in frequency of data collection can cause the differences in cyclical properties of job flows and worker flows. To deal with this issue, we solve the model at weekly frequency and the simulated weekly observations are compiled in the same way as the BLS does. This way, we can assess to what extent the differences in the cyclicality of the observed series are accounted for by the different measurement convention.

The second issue, which is more substantive, is that worker flows between unemployment and employment are only a part of all worker flows. In the literature, the attention has often been focused on this flow, mainly because researchers are interested in fluctuations in the unemployment rate. However, establishment-level data in general include all worker flows. More specifically, total separations (hires) consist of three types of flows (i) separations into (hires from) the unemployment pool, (ii) separations into (hires from) the out-of-the-labor-force pool, and (iii) separations into (hires from) other employers. Obviously, these three types of worker flows affect the behavior of job flows which are measured from establishment-level net employment changes.

This paper's interest is in simultaneously account for cyclical patterns of worker flows between employment and unemployment as well as job creation and destruction rates. To this end, we take the following strategy. First, we calibrate the model such that hires and separations that occur at the establishment level include all three types of flows. We then make three assumptions; (a) workers separated due to endogenous employment reduction go to the unemployment pool, (b) two other types of separations are lumped together into exogenous separations, and (c) all job seekers face the same job finding rate.

Are these assumptions plausible? We believe they are. First, separations associated with employer-initiated contractions of establishment size are often labeled as "layoffs" and a plausible presumption is that those workers are more likely to go to the unemployment pool. ${ }^{14}$ As shown, for example, by Fujita and Ramey (2009), the separation rate into unemployment is strongly countercyclical in the data and the behavior of endogenous separations generated from the model

\footnotetext{
${ }^{14}$ A piece of supporting evidence is that, according to the "reasons for unemployment" data in the official CPS, of all workers who are unemployed due to "layoffs" or "quits," the fraction of the former is around $80 \%$.
} 
is consistent with this empirical observation.

As for the assumption (b), first note that the separation rate into the out-of-the-labor-force pool is nearly acyclical. Our assumption of the constant separation rate is consistent with empirical evidence. ${ }^{15}$ For the remaining part of exogenous separations, first recall that the model does not feature on-the-job search and thus is unable to capture the endogenous flow associated with it. Instead, the job-to-job flow arises observed in our model as a result of time aggregation. That is, the model is simulated at weekly frequency but the data are collected at monthly frequency. Those who separate and find jobs within a month show up as the job-tojob flow in our data. We believe that the separation rate associated with the job-to-job flow is captured well with the constant rate. This appears a bit counter-intuitive given that the endogenous mechanism in the model with on-the-job search. In such models, the job-to-job transition rate naturally exhibits strong procyclicality. However, this type of prediction is rarely tested against the available evidence. ${ }^{16}$ Nagypál (2008) plots the monthly time series of the job-to-job transition rate calculated from the SIPP roughly over the period from 1996 through 2003. While it shows some gradual declines during and after the 2001 recession, whether the series is procyclical at business cycle frequency is unclear. Given this limited evidence, we believe that the assumption that the separation rate corresponding to the job-to-job flow is constant is a reasonable short cut.

The assumption (c) is made for the sake of simplicity. The assumption implies that we apply the job finding rate inferred from experience of unemployed workers to all separated workers. This simplifying assumption comes from two challenges the model faces in the calibration. First, our model features neither the labor force participation decision nor the on-the-job search. The missing heterogeneities among job seekers force us to rely on the limited evidence on the job finding rate. Second, the evidence on the size of the pool of job seekers being out of the labor force or on the job is hard to come by. While there are many studies that emphasize the importance of on-the-job search, they provide no empirical evidence on the job finding rate for those who look for jobs on the job. For those who are being out of the labor force, one could use the pool of "want-a-job" workers. However, there is a good reason to believe that the flow from

\footnotetext{
${ }^{15}$ This observation is confirmed by looking at the data constructed by Fujita and Ramey (2006) although they do not directly analyze the cyclicality of that flow in the paper.

${ }^{16}$ Recent papers which look at quantitative properties of the model with on-the-job-search include Tasci (2007) and Ramey (2008). The first paper reports the cyclicality of the job-to-job transition rate based on the simulated data and it is indeed strongly procyclical. However, he does not evaluate the empirical plausibility of the result.
} 
Table 2: Benchmark Parameter Values: Weekly Calibration

\begin{tabular}{lll}
\hline \hline Parameter & Value & Description \\
\hline$\psi$ & 0.5000 & Elasticity of matching function w.r.t. vacancies \\
$\alpha$ & 0.6700 & Curvature of production function \\
$\beta$ & 0.9990 & Time discount factor \\
$\mu$ & 0.7200 & Workers' bargaining power \\
$\tau$ & 0.1492 & Scale parameter of matching function \\
$p_{d}$ & 0.5290 & Firing cost \\
$\widetilde{d}$ & 0.0484 & Prob. of firm-level exogenous separation shock \\
$b$ & 0.1808 & Conditional prob. of exogenous separation for workers \\
$\rho_{x}$ & 0.4000 & Flow outside benefit (normalization) \\
$\sigma_{x}$ & 0.9800 & Persistence of idiosyncratic shock \\
$\kappa$ & 0.0300 & Standard deviation of idiosyncratic shock \\
$L$ & 0.0440 & Flow cost of posting a vacancy \\
$\rho_{z}$ & 11.194 & Labor force size \\
$\sigma_{z}$ & 0.9957 & Persistence of aggregate shock \\
\hline \hline
\end{tabular}

the out-of-the-labor-force may not necessarily come from this pool of workers. ${ }^{17}$ In any event, the pool of "want-a-job" workers is also strongly countercyclical and thus applying the same job finding rate to these workers does not alter our results in significant ways.

As we noted above, we solve the model at weekly frequency but collect the data according to the way the BLS collects the actual data. Creating the job flow rates is quite simple. We simply need to aggregate establishment-level net employment changes over a 12-week period. On the other hand, tracing worker flows is not as simple because we need to keep track of labor market status of all individual workers over the 4 week period. Details of this algorithm is described in Appendix A.4. (TBA)

\subsection{Parameter Values}

Table 2 summarizes the parameters of the model. The time discount factor is set to 0.999 which implies the quarterly interest rate of 1.2 percent. The elasticity of the matching function with respect to vacancies is set to 0.5 . The available evidence on this parameter, summarized in Petrongolo and Pissarides (2001), varies widely across studies. The chosen value for the benchmark calibration is on the low side within the reasonable range. We thus also examine

\footnotetext{
${ }^{17}$ See Fujita and Ramey (2006) for details.
} 
the sensitivity of the results with respect to a higher value later. We do not have tight direct evidence on the bargaining power parameter. For the benchmark calibration, we simply follow the weight (0.72) used by Mortensen and Nagypál (2007). We will later examine the case where the parameter is set to an alternative value, i.e., 0.5. Next, the curvature parameter of production is set to 0.67. The similar value is often used in the literature that looks at establishment-level employment dynamics using the same production technology (e.g., Campbell and Fisher (2000) and Cooper, Haltiwanger and Willis (2007)). Again, we will later conduct the sensitivity analysis with respect to an alternative value of this parameter. The $\mathrm{AR}(1)$ coefficient of the aggregate productivity process is set such that quarterly first-order autocorrelation coincides with 0.95 $\left(\approx 0.9957^{12}\right)$. The calibration of the standard deviation of the aggregate shock $\sigma_{z}$ is discussed later.

We target the following labor market statistics to select some of the remaining parameters. First, we target the monthly job finding rate of job seekers at $25 \%$. This roughly corresponds to the historical average of the monthly transition rate from unemployment to employment over the period of January 1976 to December 2005. ${ }^{18}$ Given the monthly-level target, we set the target for the weekly job finding rate $f(\theta)$ at $6.75 \%$. The weekly job filling rate $q(\theta)$ is targeted at $33 \%$, the value used by Ramey (2008) which is in turn based on the study by Barron, Berger and Black (1997). These two target values for $f$ and $q$ pin down steady-state labor market tightness $\theta$ at 0.205 . We can then calculate the scale parameter of the matching function $\mu$ through $f / \theta^{\psi}$.

The steady-state endogenous separation rate in the model, which, as discussed above, corresponds to the employment to unemployment transition rate. We set its target to $1.5 \%$ at monthly frequency, which equals the historical average of the data created by Fujita and Ramey (2006). The steady-state total separation rate is targeted at $5 \%$ at monthly frequency. The JOLTS (Job Openings and Labor Turnover Survey) reports the monthly total separation rate which is much smaller than 5\%. However, as shown by Davis, Faberman, Haltiwanger and Rucker (2008), the the JOLTS data seriously underestimates the level of the separation rate. They adjust the JOLTS series by using the more comprehensive BED data and show that the time series average of the adjusted JOLTS data is about 5\% over the period of January 2001 through December 2006. Given the target levels of the endogenous separation rate and the total separation rate,

\footnotetext{
${ }^{18}$ The series is adjusted for margin error and constructed by Fujita and Ramey (2006). See the paper for the data construction details. The series used to calculate the historical averages is not corrected for time aggregation error. Shimer (2007) points out the presence of time aggregation error in the CPS and proposes a way to correct it. The correction is, however, irrelevant for us because our data collection procedure is exactly the same as the one used by the BLS.
} 
the exogenous separation rate is targeted at 3.5\% at monthly frequency. Accordingly, the weekly level exogenous separation rate, $p_{d} \widetilde{d}$, is chosen to be $0.875 \%$. We will determine $p_{d}$ to be 0.0484 below, and $\widetilde{d}$ is thus chosen to be 0.181 .

The parameters for the idiosyncratic productivity process, $\rho_{x}$ and $\sigma_{x}$, and frequency of the exogenous separation shock $p_{d}$ are identified using the establishment-level information on which the three parameters have strong influence. First, the aggregate job flow rate is aimed at around $8 \%$, which roughly corresponds to the historical average of the private-sector job creation and destruction rates. Second, the average one-quarter persistence measure of job creation rate is at around 0.7. This statistic is proposed by Davis, Haltiwanger and Schuh (1996) and measures the percentage of newly created jobs at time $t$ that remain filled at the next sampling date one quarter later. They report that the historical average of this measure for the manufacturing sector over the period of 1972Q2 through 1988Q4 is $0.678 .{ }^{19}$ Lastly, we also use a piece of information in the employment growth distribution, which is reported by Davis, Faberman, Haltiwanger and Rucker (2008). Specifically, we target the fraction of establishments that have no employment experience at $15.7 \%$ as reported by these authors. Recall our assumption that at the establishment level, exogenous separation occurs only with probability $p_{d}$. This assumption is adopted to match the fraction of no employment change. ${ }^{20}$ Assigning the three parameters to match the three statistics yield $\rho_{x}=0.98, \sigma_{x}=0.03$, and $p_{d}=0.0484$.

The three parameters $b, \kappa$ and $L$ are determined as follows. First, note that one of the three parameters can be set at an arbitrary value as normalization. Accordingly we set $b=0.4{ }^{21}$ The remaining two parameters are set such that the model matches steady state levels of labor market tightness $\theta$ and the endogenous separation rate given all other parameter values. Through this process, we obtain $\kappa=0.044$ and $L=11.194$.

Finally, determining the remaining two parameters, $\sigma_{z}$, and $\tau$, we appeal to the second moment properties of the model. First, we set $\sigma_{z}$ at the level (0.0033) that delivers the aggregate output volatility of roughly $2 \%$. To see how $\tau$ is set, note that $\tau$ and the average hiring cost $\left(\frac{\kappa}{q}\right)$ have strong influences on the firm's dynamic hiring/firing decision. The latter has already

\footnotetext{
${ }^{19}$ Unfortunately, empirical evidence on this measure is available only for the manufacturing sector. The persistence measure of job destruction is defined similarly as the percentage of newly destroyed jobs at time $t$ that do not reappear at the next sampling date. Davis, Haltiwanger and Schuh (1996) report that job destruction persistence in manufacturing is 0.723 .

${ }^{20}$ The case with $p_{d}=1$ is unable to match the statistic because exogenous separations always result in declines in employment even when the firm does not actively change the employment size.

${ }^{21}$ This level by itself has no particular meaning in our paper. In the context of the volatility puzzle, what is relevant is this level relative to average labor productivity, which we will discuss shortly.
} 


\section{Table 3: Steady State Implications: Benchmark Calibration}

\begin{tabular}{|c|c|c|c|}
\hline Data & $\begin{array}{c}\text { Data collection } \\
\text { frequency }\end{array}$ & $\begin{array}{c}\text { Empirical } \\
/ \text { target }\end{array}$ & $\overline{\text { Model }}$ \\
\hline \multicolumn{4}{|l|}{ Worker-level data } \\
\hline Separation rate & Monthly & 0.015 & 0.014 \\
\hline Job finding rate & Monthly & 0.250 & 0.242 \\
\hline Unemployment rate & Monthly & 0.057 & 0.053 \\
\hline \multicolumn{4}{|l|}{ Establishment-level data } \\
\hline Total separation rate & Monthly & 0.050 & 0.045 \\
\hline Job flow rates & Quarterly & 0.080 & 0.081 \\
\hline Job flow persistence measure & Quarterly & 0.710 & 0.730 \\
\hline$b /($ average labor productivity) & - & - & 0.830 \\
\hline
\end{tabular}

Notes: See the notes to Table 1 for the sample periods of each series. The persistence measure in the data is from Davis, Haltiwanger and Schuh (1996) which covers the manufacturing sector for 1972Q2-1988Q4.

been pinned down and we thus choose $\tau$ to match the balance of the volatilities between the job destruction rate and job creation rate. The implied level of this parameter (0.529) turns out to be quite low. It amounts to $126 \%$ of average weekly wage. Our estimate from the model is consistent with the empirical evidence that the firing cost in the US is very low. ${ }^{22}$

\subsection{Steady State Properties}

Before discussing the dynamic properties of the model, let us first consider the performance of the model in the steady state. Table 3 compares model's steady state values with corresponding target values. While we are unable to achieve exact match due to the model's nonlinearity, the model delivers the steady state values broadly in line with the empirical targets.

We also examine the model's cross-sectional implications. Table 4 compares the employment growth distributions based on the simulated data and the actual data. Recall that we select the parameter values (in particular, $p_{d}$ ) to match the fraction of establishments with no net

\footnotetext{
${ }^{22}$ Despite the empirical evidence, the literature on the effects of the firing cost on labor market dynamics typically use much higher values. For example, Campbell and Fisher (2000) set the firing cost equal to $50 \%$ of quarterly wage in their benchmark calibration. Hopenhayn and Rogerson (1993) and Veracierto (2008) also use similar values. The interpretation offered by Campbell and Fisher is that it corresponds to the cost of destroying the job position. Thus it is in principle possible that the firm incurs no cost of replacing workers for the same position but incurs a larger cost in getting rid of the potion itself. However, our model does not have distinction between worker turnover and job-position turnover. Thus the correct interpretation of the firing cost in our model is the cost associated with worker turnover, which is empirically low.
} 


\section{Table 4: Employment Growth Distribution}

\begin{tabular}{|c|c|c|c|c|}
\hline \multicolumn{3}{|c|}{$\begin{array}{l}\text { Growth rate } \\
\text { interval }\end{array}$} & $\overline{\text { Empirical }}$ & $\overline{\text { Model }}$ \\
\hline & $>$ & -0.20 & 0.076 & 0.159 \\
\hline-0.20 & to & -0.05 & 0.167 & 0.194 \\
\hline-0.05 & to & -0.02 & 0.097 & 0.044 \\
\hline-0.02 & to & 0.00 & 0.078 & 0.023 \\
\hline \multicolumn{3}{|c|}{0.00} & 0.157 & 0.157 \\
\hline 0.00 & to & 0.02 & 0.080 & 0.020 \\
\hline 0.02 & to & 0.05 & 0.100 & 0.045 \\
\hline 0.05 & to & 0.20 & 0.169 & 0.169 \\
\hline 0.20 & $<$ & & 0.076 & 0.190 \\
\hline
\end{tabular}

Notes: Taken from Davis, Faberman, Haltiwanger and Rucker (2008). The table reports employment shares for the indicated quarterly employment growth rate intervals in BED micro data from 2001 to 2006 and in the steady state of the model. The empirical distribution is based on continuously existing establishments.

employment change. The table shows that the model has difficulties in replicating some of the features of the empirical growth distribution. In particular, there are too many establishments in the model making large employment changes, i.e., more than $20 \%$ increase or reduction of employment. We conjecture that this problem stems from the structure of the labor adjustment costs: in the model, the the labor adjustment costs are linear in the number of hiring or firing. In reality, such large employment adjustments may also require adjustment of capital, which could incur large fixed costs. The model completely abstracts away from such considerations. Integrating the type of model considered in this paper with, for example, the model of lumpy investment is beyond the scope of this paper at this point and thus left for future research.

\section{Computation}

We solve the model numerically since there is no analytical solution. Specifically, our solution method is based on the partial information approach developed by Krusell and Smith (1998). We utilize their method because our model faces the same problem of having a huge aggregate state variable, which is the type distribution of heterogeneous firms $m$. The essence of the approach is to limit the information that agents in the model use to a finite set of statistics summarizing the type distribution, which is the original state variable, and transform the original problem 
to a tractable approximated problem. Effectively, the approach is implemented by replacing the large state variable by a finite set (desirably very small number) of statistics that summarize the type distribution. Appendix A.3 contains details about the computational algorithm.

\section{$7 \quad$ Main Results}

\subsection{Business Cycle Statistics}

Volatilities. We first look at volatilities of the model, which is presented in Table 5. Along this dimension, the model does an excellent job. First, consider volatilities of worker flows, transition rates and job flows. Our model generates slightly larger volatilities than those of empirical counterparts. However, the model is able to mimic the empirical features that (i) the destruction rate is more volatile than the creation rate, that (ii) job finding rate is more volatile than the separation rate, that (iii) the separation flow is more volatile than the hiring flow, and that (iv) worker flows are more volatile than job flows.

The last two rows of each panel of Figure 5 show that the model is able to generate large fluctuations of unemployment and vacancies that are comparable to the data. Although vacancies fluctuate less in the model than in the data, it can be easily increased by raising the elasticity of the matching function with respect to vacancies, as we will see shortly. Recall that our calibration strategy leaves no degree of freedom of assigning parameters to match these vol atilities. In the standard seach/matching model, it is well-known that the outside option parameter $b$ plays a key role for volatilities of the model. In particular, Hagedorn and Manovskii (2008) show in their setting that when the outside option parameter is set to the level close to labor productivity, the model is able to generate large volatilities. As mentioned before, however, not all researchers accept this resolution. In response to the criticism, Elsby and Michaels (2008) recently show that with downward sloping labor demand, average surplus can be relatively large even though marginal surplus is small. Our benchmark calibration implies the level of $b$ that is $83 \%$ of average labor productivity. This is substantially lower than Hagedorn and Manovskii's value (96\%).

Another important point to note is that Elsby and Michaels (2008) only consider the steadystate elasticities. They accordingly evaluate their results in comparison to empirical elasticities calculated from regressions of labor productivity with other variables. On the other hand, our results are based on the simulations of the stochastic dynamic equilibrium and we show that the model is capable of matching unconditional volatilities. 
Table 5: Comparison of Business Cycle Properties: Volatilities

\begin{tabular}{|c|c|c|c|c|c|}
\hline & Empirical & Benchmark & $\alpha=0.4$ & $\eta=0.5$ & $\psi=0.6$ \\
\hline \multicolumn{6}{|l|}{ Standard deviation } \\
\hline \multicolumn{6}{|l|}{ Worker flows } \\
\hline Empl. to unemp. & 0.058 & 0.075 & 0.044 & 0.090 & 0.079 \\
\hline Unemp. to emp. & 0.046 & 0.042 & 0.025 & 0.051 & 0.045 \\
\hline \multicolumn{6}{|l|}{ Transition rates } \\
\hline Separation rate & 0.064 & 0.077 & 0.046 & 0.093 & 0.082 \\
\hline Job finding rate & 0.069 & 0.084 & 0.046 & 0.098 & 0.075 \\
\hline \multicolumn{6}{|l|}{ Job flows } \\
\hline Creation rate & 0.027 & 0.053 & 0.030 & 0.061 & 0.048 \\
\hline Destruction rate & 0.031 & 0.055 & 0.031 & 0.064 & 0.054 \\
\hline \multicolumn{6}{|l|}{ Stocks } \\
\hline Unemployment rate & 0.100 & 0.114 & 0.065 & 0.138 & 0.113 \\
\hline Vacancies & 0.130 & 0.120 & 0.066 & 0.139 & 0.147 \\
\hline \multicolumn{6}{|c|}{ SD relative to SD of labor productivity } \\
\hline \multicolumn{6}{|c|}{ Worker flows } \\
\hline Empl. to unemp. & 7.587 & 8.721 & 5.465 & 11.080 & 9.008 \\
\hline Unemp. to emp. & 6.056 & 4.845 & 3.079 & 6.336 & 5.161 \\
\hline \multicolumn{6}{|l|}{ Transition rates } \\
\hline Separation rate & 8.431 & 8.941 & 5.624 & 11.416 & 9.323 \\
\hline Job finding rate & 9.130 & 9.715 & 5.697 & 12.098 & 8.564 \\
\hline \multicolumn{6}{|l|}{ Job flows } \\
\hline Creation rate & 4.512 & 6.158 & 3.665 & 7.550 & 5.507 \\
\hline Destruction rate & 5.143 & 6.335 & 3.864 & 7.875 & 6.115 \\
\hline \multicolumn{6}{|l|}{ Stocks } \\
\hline Unemployment rate & 13.148 & 13.251 & 7.996 & 16.993 & 12.862 \\
\hline Vacancies & 17.097 & 13.917 & 8.129 & 17.203 & 16.733 \\
\hline
\end{tabular}

Correlations. Table 6 considers the correlation patterns with respect to average labor productivity. First, observe that the model replicates the countercyclical separation rates into unemployment and the procyclical job finding rate. The key result is that the model can capture the differences in the cyclicality of worker flows and job flows. That is, the model generates the procyclical job creation rate and countercyclical job destruction rate while maintaining the countercyclicality of worker flows. The fact that the model is able to capture the countercyclicality of separations and the job destruction rate is not surprising; it is a direct consequence of 
Table 6: Comparison of Business Cycle Properties: Correlations

\begin{tabular}{|c|c|c|c|c|c|}
\hline & Empirical & Benchmark & $\alpha=0.4$ & $\eta=0.5$ & $\psi=0.6$ \\
\hline \multicolumn{6}{|c|}{ Corr with labor productivity } \\
\hline \multicolumn{6}{|c|}{ Worker flows } \\
\hline Empl. to unemp. & -0.579 & -0.669 & -0.693 & -0.737 & -0.726 \\
\hline Unemp. to emp. & -0.347 & -0.236 & -0.272 & -0.264 & -0.396 \\
\hline \multicolumn{6}{|l|}{ Transition rates } \\
\hline Separation rate & -0.579 & -0.775 & -0.799 & -0.827 & -0.810 \\
\hline Job finding rate & 0.415 & 0.961 & 0.980 & 0.948 & 0.962 \\
\hline \multicolumn{6}{|l|}{ Job flows } \\
\hline Creation rate & 0.293 & 0.444 & 0.433 & 0.469 & 0.381 \\
\hline Destruction rate & -0.455 & -0.601 & -0.618 & -0.647 & -0.623 \\
\hline \multicolumn{6}{|l|}{ Stocks } \\
\hline Unemployment rate & -0.448 & -0.880 & -0.893 & -0.861 & -0.884 \\
\hline Vacancies & 0.572 & 0.979 & 0.991 & 0.979 & 0.980 \\
\hline
\end{tabular}

the countercyclical separation rate into unemployment. ${ }^{23}$ Further, the countercyclicality of hires from the unemployment pool also comes from the countercylicality of the separation rate and thus unemployment, as discussed elsewhere in the paper.

Why is the job creation rate procyclical? The presence of large hiring flows governed by the exogenous component of separations plays a key role. Note that in the model economy, there is a flow of workers that separate from their employer independently of the firm-level idiosyncratic shocks and aggregate shock and that this flow occurs at a constant rate of aggregate employment. However, because of the lower job finding rate in downturns, hires from the non-unemployed pool of job seekers go down. In other words, the flow associated with the exogenous component of separations is procyclical. Furthermore, as we saw in the calibration section, a share of the separation flow into unemployment is less than a third of the total separations. The job creation rate, which in principle counts all hiring flows, then becomes procyclical. ${ }^{24}$ The result suggests that obtaining a unified picture of the labor market requires heterogeneity of worker flows together with the careful calibration of the model.

Next, consider the cyclicality of unemployment and vacancies. The model generates the strong countercyclicality of unemployment and strong procyclicality of vacancies. The latter

\footnotetext{
${ }^{23}$ Strictly speaking, the countercyclicality of the destruction rate is less clear because the link with the separation rate is not less tight. We will come back to this issue shortly.

${ }^{24}$ Again, there is an issue of time aggregation associated with the quarterly definition of job flows, but we will examine this issue below.
} 
result is notable in the sense that the standard search/matching models with the endogenous separation decision (such as the model of Mortensen and Pissarides (1994) or its DSGE version by Den Haan, Ramey and Watson (2000)) are unable to replicate the countercyclicality. ${ }^{25}$

One major drawback of the model is lack of the strong propagation mechanism, which is also a problem of the standard model (Fujita and Ramey (2007)). This problem can be seen in much stronger correlations of unemployment and vacancies with labor productivity than those observed in the data. In essence, labor adjustments of the model is concentrated at the onset of the shock. Examining impulse responses makes this point clearer.

\subsection{Impulse Responses.}

Figure 5 plots impulse responses of the model to the $1 \%$ negative aggregate shock. Note that in the figure, we distinguish between the number of job creation and destruction (Figure 5(b)) and rates of job creation and destruction (Figure 5(c)). First consider Figure 5(a) where worker flows between unemployment and employment are plotted. Note first that, in the impact period, the separation flow into and hiring flow from unemployment move in the opposite direction. However, the decline in the hiring flow is only one third of the increase in the separation flow. This is because some of the initial declines within the quarter are already reversed toward the end of the quarter as the unemployment pool expands. In the second quarter, the initial decline in the flow from unemployment is completely eliminated, reaching a much higher level than the steady state level. On the other hand, Figure 4(b) shows that the initial decline in job creation is twice as large as the decline in the unemployment-to-employment flow and that the bounce-back of job creation from the second quarter on is much less pronounced.

Next, observe that the response of the stock of unemployment, shown in Figure 5(d), exhibits a small hump. Note that the difference between separations and hires plotted in Figure 5(a) corresponds to the change in unemployment. The behavior of worker flows implies that the changes in unemployment are positive only up to the second quarter. From the third quarter on unemployment starts to decline.

We can draw two general important implications from the impulse responses. First, the analysis based on the dynamic stochastic equilibrium is quite different from the one based on the steady state analysis. In the literature, magnification of the model is often inferred from the steady-state elasticity because "labor market turnover is fast." However, by definition, the steady state analysis implies that labor market flows in the opposite directions are always equated. As

\footnotetext{
${ }^{25}$ The correlation between the two variables, which is not reported in Table 6 , is -0.86 in the model.
} 
(a) Worker flows

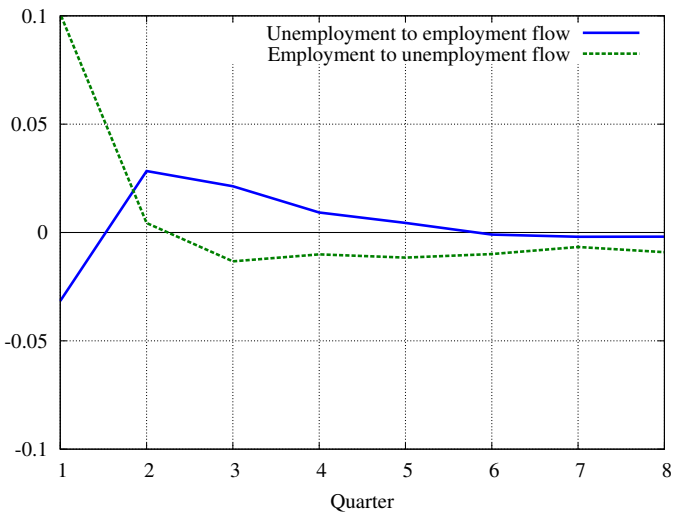

(c) Job creation ad destruction rate

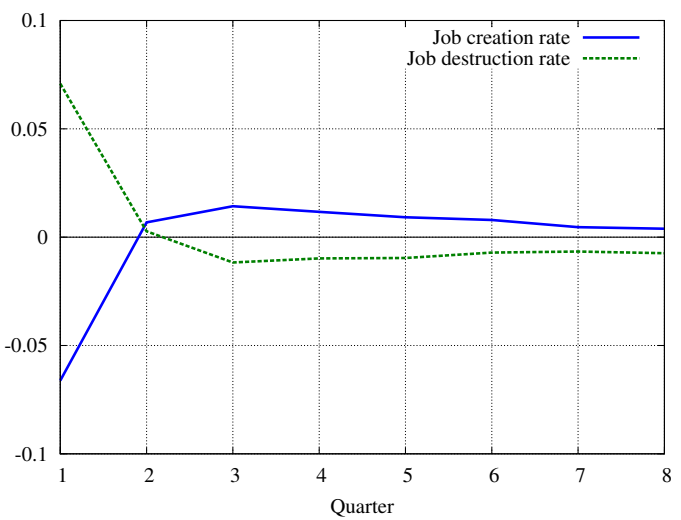

(b) Job creation and destruction

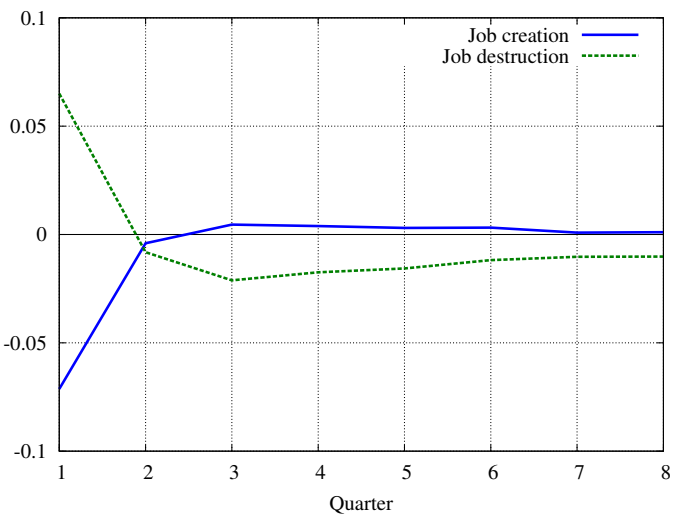

(d) Unemployment, vacancies and transition rates

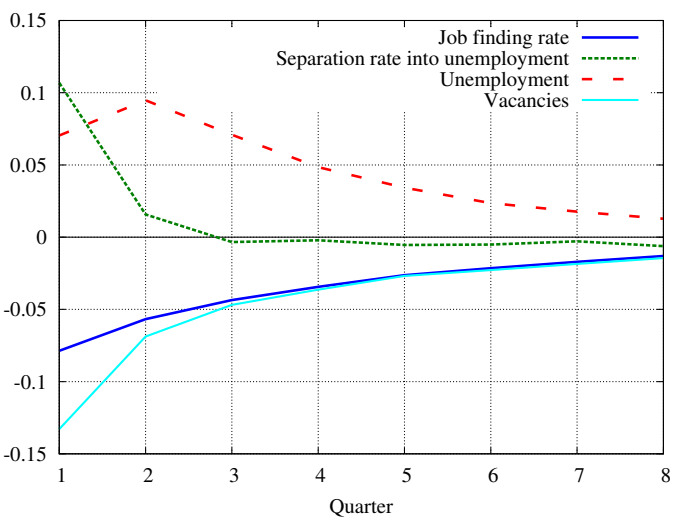

Figure 5: Impulse responses in the baseline economy

Notes: Plotted are responses to the $-1 \%$ aggregate shock expressed as deviations from the steady-state levels. Job flows and job flow rates are based on the establishmentlevel net employment changes over a quarterly period. Quarterly worker flows, transition rates, unemployment are averages of monthly series.

is clear from the dynamics of the model shown in Figure 5, this condition is far from satisfied especially in the short run. In particular, the increase in unemployment in the impact quarter is largely explained by the difference between the hiring flow and separation flow.

Secondly, the impulse responses shown in the figure clearly shows lack of the propagation mechanism in the model. In particular, the effects on the endogenous separation rate mostly die away in two quarters and it reaches back to the steady-state level in the third quarter. Accordingly, the effects of the aggregate shock on the employment-to-unemployment flow as well as job destruction are concentrated in the first quarter. Empirically, the response of the separation rate and the associated flow is known to be much more persistent (e.g., Fujita (forthcoming)). 
Table 7: Effect of Time Aggregation for Job Flow Data

\begin{tabular}{lccc}
\hline \hline \multicolumn{1}{c}{ Empirical } & Model & $\begin{array}{c}\text { Model } \\
\text { (Avg of weekly) }\end{array}$ \\
\hline Standard deviation & & & \\
Creation rate & 0.027 & 0.053 & 0.045 \\
Destruction rate & 0.031 & 0.055 & 0.044 \\
\hline SD relative to SD of labor productivity & \\
Creation rate & 4.512 & 6.158 & 5.227 \\
Destruction rate & 5.143 & 6.335 & 5.144 \\
\hline Corr with labor productivity & & \\
Creation rate & 0.293 & 0.444 & 0.411 \\
Destruction rate & -0.455 & -0.601 & -0.633 \\
\hline \hline
\end{tabular}

It is also known that the job destruction rate is more persistent in the data than in the model, even though the evidence is limited to the manufacturing job destruction rate (e.g., Davis and Haltiwanger (1999)). In other words, the model implausibly implies too much "cleansing effect" in the short run. Furthermore, the lack of persistence in the separation rate makes it difficult for the model to generate the empirically plausible unemployment response which exhibits a much more pronounced hump shape.

\subsection{Effects of Time Aggregation}

One potential reason why job flows and worker flows behave differently could be attributed to the different measurement practices. In particular, job flows are measured from net employment changes over a quarterly period while worker flows are measured monthly. In Table 7 , we present the business cycle statistics based on quarterly averages of weekly job flows in comparison to those based on the actual definitions of job flows. Since job flows are identical to worker flows at weekly frequency, this comparison reveals the extent to which the measurement practice accounts for the differences.

The result indicates that using the definitions based on net employment changes over a quarter increase the volatilities of job flows. However, the discrepancies are not of quantitatively serious magnitude. As for the cyclicality of job flows, the two definitions give roughly the same correlation patterns. We thus conclude that time aggregation plays a minor role in explaining the differences in the behavior of job flows and worker flows. 


\section{Table 8: Parameter Values: Alternative Calibrations}

\begin{tabular}{lccc}
\hline \hline & \multicolumn{3}{c}{ Alternative calibrations } \\
Parameter & lower $\alpha$ & lower $\eta$ & higher $\psi$ \\
\hline$\psi$ & 0.5000 & 0.5000 & $\mathbf{0 . 6 0 0 0}$ \\
$\alpha$ & $\mathbf{0 . 4 0 0 0}$ & 0.6700 & 0.6700 \\
$\beta$ & 0.9990 & 0.9990 & 0.9990 \\
$\eta$ & 0.7200 & $\mathbf{0 . 5 0 0 0}$ & 0.7200 \\
$\mu$ & 0.1492 & 0.1492 & 0.1273 \\
$\tau$ & 0.1345 & 0.1564 & 0.0897 \\
$p_{d}$ & 0.0465 & 0.0406 & 0.0406 \\
$\widetilde{d}$ & 0.1882 & 0.2155 & 0.2158 \\
$b$ & 0.4000 & 0.4000 & 0.4000 \\
$\rho_{x}$ & 0.9900 & 0.9800 & 0.9800 \\
$\sigma_{x}$ & 0.0500 & 0.0300 & 0.0300 \\
$\kappa$ & 0.0222 & 0.0129 & 0.0074 \\
$L$ & 2.4327 & 8.1544 & 10.220 \\
$\rho_{z}$ & 0.9957 & 0.9957 & 0.9957 \\
$\sigma_{z}$ & 0.0330 & 0.0330 & 0.0330 \\
\hline \hline
\end{tabular}

\section{Sensitivity Analysis}

In this section, we conduct the sensitivity analysis with respect to three alternative calibrations: (i) lower curvature parameter of the production function (0.4), (ii) lower bargaining power of workers (0.5), and (iii) higher elasticity of the matching function with respect to vacancies (0.6). For each case, we re-calibrate the model following the same procedure as the benchmark calibration. In other words, the same moment conditions are maintained and thus each of the parameter changes also involves changes in other parameter values. However, we use the same parameter values for the aggregate TFP process.

Table 8 presents all parameter values for the three cases. Tables 9 and 10 present associated steady-state properties of the model under the three calibrations. These two tables show that the three models share roughly the same steady-state properties as the benchmark model. The last row of Table 9, however, shows that the three models differ in one important dimension. The ratio of the outside option parameter to average labor productivity varies depending on the calibration. Remember that we do not have a degree of freedom to target this value, and thus the implied ratios are endogenous outcome of the calibrations. The variations of the relative level of $b$ provides us with a natural way of examining the strength of the magnification mechanism of the alternative calibrations. 
Table 9: Steady State Values: Alternative Calibrations

\begin{tabular}{lccc}
\hline \hline Data & $\alpha=0.4$ & $\eta=0.50$ & $\psi=0.60$ \\
\hline Worker-level data & & & \\
$\quad$ Separation rate & 0.014 & 0.0136 & 0.014 \\
Job finding rate & 0.242 & 0.242 & 0.242 \\
Unemployment rate & 0.053 & 0.053 & 0.053 \\
\hline Establishment-level data & & & \\
$\quad$ Total separation rate & 0.045 & 0.044 & 0.045 \\
$\quad$ Job flow rates & 0.083 & 0.081 & 0.081 \\
$\quad$ Job flow persistence measure & 0.737 & 0.730 & 0.730 \\
\hline b/(average labor productivity) & 0.635 & 0.770 & 0.830 \\
\hline \hline
\end{tabular}

\section{Table 10: Employment Growth Distribution with Alternative Calibrations}

\begin{tabular}{cc|ccc}
\hline \hline \multicolumn{2}{c|}{$\begin{array}{c}\text { Growth rate } \\
\text { interval }\end{array}$} & $\alpha=0.4$ & $\eta=0.50$ & $\psi=0.60$ \\
\hline & $>-0.20$ & 0.137 & 0.160 & 0.160 \\
-0.20 to -0.05 & 0.225 & 0.194 & 0.194 \\
-0.05 to -0.02 & 0.043 & 0.044 & 0.044 \\
-0.02 to 0.00 & 0.021 & 0.023 & 0.023 \\
0.00 & 0.157 & 0.157 & 0.157 \\
0.00 & to $\quad 0.02$ & 0.018 & 0.020 & 0.020 \\
0.02 to 0.05 & 0.041 & 0.044 & 0.045 \\
0.05 to 0.20 & 0.166 & 0.170 & 0.169 \\
$0.20<$ & 0.192 & 0.189 & 0.190 \\
\hline \hline
\end{tabular}

\subsection{Business Cycle Statistics}

Volatilities. The last three columns of Table 5 give the volatility measures for the three alternative calibrations. Overall, the last case $(\phi=0.6)$ gives the best performance among the three. The only dimension that this calibration fails to match is the empirical fact that the job finding rate is more volatile than the separation rate (the model implies the opposite). However, it achieves almost perfect match of volatilities of unemployment and vacancies, which the benchmark calibration fails to achieve. Note also that the last row of Table 9 suggests that the benchmark calibration and the calibration with $\phi=0.6$ share the same level of $b$ relative to aggregate labor productivity.

The calibration with lower $\alpha$ underpredicts volatilities. This can be understood again from the level of $b$, which is $64 \%$ of average labor productivity. However, even with this level of $b$, roughly $60 \%$ of the unemployment volatility can be explained. On the other hand, the calibration 
with lower bargaining power of workers generates larger volatilities than observed data. This is achieved even with the level of $b$ that is $77 \%$ of average labor productivity. This appears to suggest that giving lower bargaining power to workers raise volatilities of the model for the same relative level of $b$, as is the case in the standard model. ${ }^{26}$

Correlations. The last three columns of Table 6 present the correlations with aggregate labor productivity. While correlations vary with alternative calibrations, none of the key results from the benchmark calibration are overturned, suggesting the robustness of the model's correlation pattern.

\section{Applications}

Having established that the model's quantitative properties are consistent with empirical observations, we now ask the following three important questions using the benchmark model.

\subsection{Job Destruction in the Model with No Endogenous Separations}

The first question entails the usefulness of the measured job destruction rate as a measure of firm-initiated employment reduction. More specifically, measured job destruction can be affected whenever an establishment reduces the stock of employment over a quarterly period regardless of the sources of the employment change, and thus it may not necessarily reflect firm-initiated employment reduction. Consider a case where employment declines as a result of exogenous worker turnover that the firm decides not to replace immediately. This may be the optimal choice for the firm when laying off workers incurs large costs. If the firm follows this employment policy, measured job destruction loses its usefulness as a measure of firm-initiated employment reduction.

To infer upper-bound of this effect, we deliberately shut down the channel of endogenous job destruction and see how much the job destruction rate can fluctuate only through the channel of the no-replacement policy. This case is equivalent of imposing the infinite cost on endogenous job destruction. ${ }^{27}$

\footnotetext{
${ }^{26}$ For the effect of changing the bargaining power parameter on the steady-state elasticity of market tightness, see for example Mortensen and Nagypál (2007).

${ }^{27}$ Although the model is based on the benchmark calibration, some adjustments of calibration is necessary. For example, we target the size of the total monthly separation rate at $5 \%$ as in the benchmark case. However, since all separations occur through exogenous separations, we set $p_{d} \widetilde{d}=0.0125$ instead of 0.00875 . We then chose $p_{d}$ to achieve the fraction of establishments with no employment change at 0.157 . This procedure results in $p_{d}=0.115$
} 
Table 11: Experiment with No Endogenous Separations

\begin{tabular}{lccc}
\hline \hline & Empirical & $\begin{array}{c}\text { Benchmark } \\
\text { model }\end{array}$ & $\begin{array}{c}\text { No endog. } \\
\text { separations }\end{array}$ \\
\hline $\begin{array}{l}\text { Standard deviation } \\
\text { Job flows }\end{array}$ & & \\
$\quad$ Creation rate & 0.027 & 0.053 & 0.041 \\
$\quad$ Destruction rate & 0.031 & 0.055 & 0.023 \\
Transition rates & & & \\
$\quad$ Job finding rate & 0.069 & 0.084 & 0.052 \\
$\quad$ Separation rate & 0.064 & 0.077 & 0.000 \\
\hline $\begin{array}{l}\text { SD relative to SD of labor productivity } \\
\text { Job flows }\end{array}$ & & \\
$\quad$ Creation rate & 4.512 & 6.158 & 4.008 \\
$\quad$ Destruction rate & 5.143 & 6.335 & 2.306 \\
Transition rates & & \\
$\quad$ Job finding rate & 9.130 & 9.715 & 5.060 \\
$\quad$ Separation rate & 8.431 & 8.941 & 0.000 \\
\hline Corr with labor productivity & & \\
Job flows & & & \\
$\quad$ Creation rate & 0.293 & 0.444 & 0.580 \\
$\quad$ Destruction rate & -0.455 & -0.601 & -0.568 \\
Transition rates & & & \\
$\quad$ Job finding rate & -0.579 & 0.961 & 0.979 \\
$\quad$ Separation rate & & & \\
\hline \hline
\end{tabular}

Results. Table 11 presents the results from this exercise. Let us first start with the bottom part of the table. Interestingly, even without endogenous separations, the measured job destruction rate exhibits strongly countercyclicality. This is because, during downturns, more establishments decide not to replace workers that left the establishment for exogenous reasons.

Now consider the middle panel of the table which compares relative volatilities of the job destruction rate as well as other variables of interest. It shows that the the volatility of the job destruction rate in the model is roughly $45 \%$ of the observed level. While it is arguably smaller than the necessary level, readers may find it somewhat surprising that the model without the endogenous separation decision can generate such non-trivial fluctuations in the job destruction rate. However, there are two caveats in interpreting this result. First, this number is an upperbound as mentioned above. In the model, the firms are restricted from actively shedding workers.

and $\widetilde{d}=0.109$. Further, we reset the vacancy posting cost $\kappa$ at 0.035 to achieve the same level of $b$ relative to average labor productivity $(83 \%)$ as in the benchmark calibration. 
In other words, the result is based on the firms' employment policy that is optimal only when endogenous job destruction imposes infinite costs on the firms. Furthermore, as can be seen in the last row of each panel, the model generates no variations in the separation rate by construction. This is simply inconsistent with the facts about the separation rate.

Another notable result in this experiment is that the volatility of the job finding rate is reduced by roughly $50 \%$ relative to the benchmark case (from 9.7 to 5.1 in terms of the relative volatility). This result is consistent with the analytical result shown by Elsby and Michaels (2008). They conduct an exercise similar to our experiment and calculate the steady-state elasticity of the job finding rate with and without endogenous separations. They also show that shutting off endogenous separations reduces fluctuations of the job finding rate and that the size of the reduction is not trivial. From our exercise here, Ww conclude that the model with no endogenous separation decision results in highly counterfactual behavior of not only the separation rate but also the job destruction rate.

\subsection{Reallocation of Labor and Endogenous Productivity Dynamics}

TBA

\subsection{Nonlinearity and Asymmetry of Business Cycles}

TBA

\section{Conclusion}

This paper has provided a quantitative investigation of the search/matching model with multipleworker firms. We carefully calibrate the model using empirical facts about worker flows and job flows. Our first main result is that the model can account for the important differences in the cyclical behavior of worker flows and job flows. In particular, the model is able to replicate countercyclical hires from unemployment and the procyclical job creation rate. We show that the key to this result is to allow for the large hiring flow that does not go through unemployment, for which procyclicality of the job finding rate dominates its cyclicality. We show that the model with multiple-worker firms can fully account for volatilities of unemployment and vacancies when the outside option parameter is around $80 \%$ of aggregate labor productivity. While Elsby and

Michaels (2008) has shown through the steady state comparative static that this version of 
the search/matching model has a stronger magnification mechanism, we show through impulse response functions that the volatility results come largely from short-run deviations from the steady state.

We identify lack of propagation as the main drawback of the model. The effects of the aggregate shock mostly die away in two quarters. However, the labor market adjustments in reality are known to be much more long-lasting. Our model features only search/matching cost on the hiring side and the linear firing cost on the separation side. Enriching the cost structure can potentially enhance the propagation mechanism of the model. Furthermore, absence of physical capital from our model limits its usefulness as a general equilibrium business cycle model. We believe that this is an ambitious yet important future research subject.

\section{Appendix A}

\section{A.1 Derivation of the Wage Equation}

We start from the Bellman equation for the job seekers.

$$
\begin{aligned}
W_{s}\left(z, m^{\prime}\right)=b+\beta \int(1 & \left.-f\left(z^{\prime}, m^{\prime}\right)\right) W_{s}\left(z^{\prime}, m^{\prime \prime}\right) d G_{z}\left(z^{\prime} \mid z\right) \\
& +\beta \iint f\left(z^{\prime}, m^{\prime}\right) W_{e}\left(z^{\prime}, x^{\prime}, d^{\prime}, m^{\prime \prime}, n^{\prime \prime}\right) d G_{f}\left(x^{\prime}, d^{\prime}, n^{\prime \prime}\right) d G_{z}\left(z^{\prime} \mid z\right)
\end{aligned}
$$

This can be transformed into:

$$
\begin{aligned}
W_{s}\left(z, m^{\prime}\right) & =b+\beta \int W_{s}\left(z^{\prime}, m^{\prime \prime}\right) d G_{z}\left(z^{\prime} \mid z\right) \\
& +\beta \iint f\left(z^{\prime}, m^{\prime}\right)\left[W_{e}\left(z^{\prime}, x^{\prime}, d^{\prime}, m^{\prime \prime}, n^{\prime \prime}\right)-W_{s}\left(z^{\prime}, m^{\prime \prime}\right)\right] d G_{f}\left(x^{\prime}, d^{\prime}, n^{\prime \prime}\right) d G_{z}\left(z^{\prime} \mid z\right)
\end{aligned}
$$

Using the Nash bargaining solution (7):

$$
\begin{aligned}
W_{s}\left(z, m^{\prime}\right)=b & +\beta \int W_{s}\left(z^{\prime}, m^{\prime \prime}\right) d G_{z}\left(z^{\prime} \mid z\right) \\
& +\beta \iint f\left(z^{\prime}, m^{\prime}\right) \frac{\eta}{1-\eta}\left[J\left(z^{\prime}, x^{\prime}, d^{\prime}, m^{\prime \prime}, n^{\prime \prime}\right)+\tau\right] d G_{f}\left(x^{\prime}, d^{\prime}, n^{\prime \prime}\right) d G_{z}\left(z^{\prime} \mid z\right)
\end{aligned}
$$

Using (5) (the formula for $J$ ):

$$
\begin{aligned}
W_{s}\left(z, m^{\prime}\right) & =b+\beta \int W_{s}\left(z^{\prime}, m^{\prime \prime}\right) d G_{z}\left(z^{\prime} \mid z\right)+\beta \iint f\left(z^{\prime}, m^{\prime}\right) \frac{\eta}{1-\eta}\left[z^{\prime} x^{\prime} F^{\prime}\left(n^{\prime \prime}\right)-w\left(z^{\prime}, x^{\prime}, d^{\prime}, m^{\prime \prime}, n^{\prime \prime}\right)\right. \\
& \left.-w_{n}\left(z^{\prime}, x^{\prime}, d^{\prime}, m^{\prime \prime}, n^{\prime \prime}\right) n^{\prime \prime}+\beta D\left(z^{\prime}, x^{\prime}, d^{\prime}, m^{\prime \prime}, n^{\prime \prime}\right)+\tau\right] d G_{f}\left(x^{\prime}, d^{\prime}, n^{\prime \prime}\right) d G_{z}\left(z^{\prime} \mid z\right) \quad(31)
\end{aligned}
$$


Notice that job seekers are only matched to hiring firms $\left(n^{\prime \prime}>\left(1-d^{\prime}\right) n^{\prime}\right)$. We can use the first order condition for hiring firms (17) to obtain the following:

$$
\begin{aligned}
& W_{s}\left(z, m^{\prime}\right)=b+\beta \int W_{s}\left(z^{\prime}, m^{\prime \prime}\right) d G_{z}\left(z^{\prime} \mid z\right) \\
& \quad+\beta \int f\left(z^{\prime}, m^{\prime}\right) \frac{\eta}{1-\eta}\left[\frac{\kappa}{q\left(z^{\prime}, m^{\prime}\right)}+\tau\right] d G_{z}\left(z^{\prime} \mid z\right)
\end{aligned}
$$

Notice that we can eliminate integration with respect to $G_{f}\left(x^{\prime}, d^{\prime}, n^{\prime \prime}\right)$ since the expression inside the integral is independent of firms' different individual types.

We move on to the Bellman equation for employed workers:

$$
\begin{aligned}
& W_{e}\left(z, x, d, m^{\prime}, n^{\prime}\right)=w\left(z, x, d, m^{\prime}, n^{\prime}\right) \\
& +\beta \iiint\left(d^{\prime}+\left(1-d^{\prime}\right) \mathcal{I}_{n^{\prime \prime}<\left(1-d^{\prime}\right) n^{\prime}} \frac{\left(1-d^{\prime}\right) n^{\prime}-n^{\prime \prime}}{\left(1-d^{\prime}\right) n^{\prime}}\right) W_{s}\left(z^{\prime}, m^{\prime \prime}\right) \\
& +\left(1-d^{\prime}\right)\left(\mathcal{I}_{n^{\prime \prime}>\left(1-d^{\prime}\right) n^{\prime}}+\mathcal{I}_{n^{\prime \prime}=\left(1-d^{\prime}\right) n^{\prime}}+\mathcal{I}_{n^{\prime \prime}<\left(1-d^{\prime}\right) n^{\prime}} \frac{n^{\prime \prime}}{\left(1-d^{\prime}\right) n^{\prime}}\right) W_{e}\left(z^{\prime}, x^{\prime}, d^{\prime}, m^{\prime \prime}, n^{\prime \prime}\right) \\
& d G_{d}\left(d^{\prime} \mid d\right) d G_{x}\left(x^{\prime} \mid x\right) d G_{z}\left(z^{\prime} \mid z\right)
\end{aligned}
$$

Separating out $W_{s}\left(z^{\prime}, m^{\prime \prime}\right)$, the above equation can be converted into:

$$
\begin{aligned}
& W_{e}\left(z, x, d, m^{\prime}, n^{\prime}\right)=w\left(z, x, d, m^{\prime}, n^{\prime}\right)+\beta \int W_{s}\left(z^{\prime}, m^{\prime \prime}\right) d G_{z}\left(z^{\prime} \mid z\right) \\
& +\beta \iiint\left(1-d^{\prime}\right)\left[W_{e}\left(z^{\prime}, x^{\prime}, d^{\prime}, m^{\prime \prime}, n^{\prime \prime}\right)-W_{s}\left(z^{\prime}, m^{\prime \prime}\right)\right] \\
& \quad\left(\mathcal{I}_{n^{\prime \prime}>\left(1-d^{\prime}\right) n^{\prime}}+\mathcal{I}_{n^{\prime \prime}=\left(1-d^{\prime}\right) n^{\prime}}+\mathcal{I}_{n^{\prime \prime}<\left(1-d^{\prime}\right) n^{\prime}} \frac{n^{\prime \prime}}{\left(1-d^{\prime}\right) n^{\prime}}\right) d G_{d}\left(d^{\prime} \mid d\right) d G_{x}\left(x^{\prime} \mid x\right) d G_{z}\left(z^{\prime} \mid z\right)
\end{aligned}
$$

Using the Nash bargaining solution (7):

$$
\begin{aligned}
& W_{e}\left(z, x, d, m^{\prime}, n^{\prime}\right)=w\left(z, x, d, m^{\prime}, n^{\prime}\right)+\beta \int W_{s}\left(z^{\prime}, m^{\prime \prime}\right) d G_{z}\left(z^{\prime} \mid z\right) \\
& +\beta \frac{\eta}{1-\eta} \iiint\left(1-d^{\prime}\right)\left[J\left(z^{\prime}, x^{\prime}, d^{\prime}, m^{\prime \prime}, n^{\prime \prime}\right)+\tau\right] \\
& \quad\left(\mathcal{I}_{n^{\prime \prime}>\left(1-d^{\prime}\right) n^{\prime}}+\mathcal{I}_{n^{\prime \prime}=\left(1-d^{\prime}\right) n^{\prime}}+\mathcal{I}_{n^{\prime \prime}<\left(1-d^{\prime}\right) n^{\prime}} \frac{n^{\prime \prime}}{\left(1-d^{\prime}\right) n^{\prime}}\right) d G_{d}\left(d^{\prime} \mid d\right) d G_{x}\left(x^{\prime} \mid x\right) d G_{z}\left(z^{\prime} \mid z\right)
\end{aligned}
$$

Applying the formula of $J$, (5), and the first order condition for different cases, (17), we can 
obtain the following:

$$
\begin{aligned}
& W_{e}\left(z, x, d, m^{\prime}, n^{\prime}\right)=w\left(z, x, d, m^{\prime}, n^{\prime}\right)+\beta \int W_{s}\left(z^{\prime}, m^{\prime \prime}\right) d G_{z}\left(z^{\prime} \mid z\right) \\
& +\beta \frac{\eta}{1-\eta} \iiint\left(1-d^{\prime}\right)\left[\mathcal{I}_{n^{\prime \prime}>\left(1-d^{\prime}\right) n^{\prime}}\left(\frac{\kappa}{q\left(z^{\prime}, m^{\prime}\right)+\tau}\right)+\mathcal{I}_{n^{\prime \prime}=\left(1-d^{\prime}\right) n^{\prime}}\left[J\left(z^{\prime}, x^{\prime}, d^{\prime}, m^{\prime \prime}, n^{\prime \prime}\right)+\tau\right]\right] \\
& d G_{d}\left(d^{\prime} \mid d\right) d G_{x}\left(x^{\prime} \mid x\right) d G_{z}\left(z^{\prime} \mid z\right)
\end{aligned}
$$

The term associated with firing firms drop out of the equation because the first order condition implies $J\left(z^{\prime}, x^{\prime}, d^{\prime}, m^{\prime \prime}, n^{\prime \prime}\right)+\tau=0$ for firing firms.

Now, plug what we obtained above and (5) into the Nash bargaining solution (7), we obtain:

$$
\begin{aligned}
& w\left(z, x, d, m^{\prime}, n^{\prime}\right)-b-\beta \int f\left(z^{\prime}, m^{\prime}\right) \frac{\eta}{1-\eta}\left[\frac{\kappa}{q\left(z^{\prime}, m^{\prime}\right)}+\tau\right] d G_{z}\left(z^{\prime} \mid z\right) \\
& =\frac{\eta}{1-\eta}\left[z x F^{\prime}\left(n^{\prime}\right)-w\left(z, x, d, m^{\prime}, n^{\prime}\right)-w_{n}\left(z, x, d, m^{\prime}, n^{\prime}\right) n^{\prime}+\tau-\beta \int\left(1-d^{\prime}\right) \tau d G_{d}\left(d^{\prime} \mid d\right)\right]
\end{aligned}
$$

Solve this equation for $w\left(z, x, d, m^{\prime}, n^{\prime}\right)$ gives us the following wage equation:

$$
\begin{aligned}
& w\left(z, x, d, m^{\prime}, n^{\prime}\right)=(1-\eta) b+\eta\left[z x F^{\prime}\left(n^{\prime}\right)-w_{n}\left(z, x, d, m^{\prime}, n^{\prime}\right) n^{\prime}\right. \\
& \left.+\tau\left(1-\beta+\beta \int d^{\prime} d G_{d}\left(d^{\prime} \mid d\right)\right)+\beta \int f\left(z^{\prime}, m^{\prime}\right)\left(\tau+\frac{\kappa}{q\left(z^{\prime}, m^{\prime}\right)}\right) d G_{z}\left(z^{\prime} \mid z\right)\right]
\end{aligned}
$$

\section{A.2 Derivation of the Wage Function}

Assuming $F(n)=n^{\alpha}$, the wage equation becomes:

$$
\begin{aligned}
& w\left(z, x, d, m^{\prime}, n^{\prime}\right)=(1-\eta) b+\eta\left[z x \alpha n^{\prime \alpha-1}-w_{n}\left(z, x, d, m^{\prime}, n^{\prime}\right) n^{\prime}\right. \\
& \left.+\tau\left(1-\beta+\beta \int d^{\prime} d G_{d}\left(d^{\prime} \mid d\right)\right)+\beta \int f\left(z^{\prime}, m^{\prime}\right)\left(\tau+\frac{\kappa}{q\left(z^{\prime}, m^{\prime}\right)}\right) d G_{z}\left(z^{\prime} \mid z\right)\right]
\end{aligned}
$$

We use guess and verify. Guess the following wage function (which is equation (22)).

$$
\begin{aligned}
& w\left(z, x, d, m^{\prime}, n^{\prime}\right)=(1-\eta) b+\eta\left[\frac{z x \alpha n^{\prime \alpha-1}}{1-\eta(1-\alpha)}\right. \\
& \left.+\tau\left(1-\beta+\beta \int d^{\prime} d G_{d}\left(d^{\prime} \mid d\right)\right)+\beta \int f\left(z^{\prime}, m^{\prime}\right)\left(\tau+\frac{\kappa}{q\left(z^{\prime}, m^{\prime}\right)}\right) d G_{z}\left(z^{\prime} \mid z\right)\right]
\end{aligned}
$$

Taking derivative of the function above, we obtain:

$$
w_{n}\left(z, x, d, m^{\prime}, n^{\prime}\right)=\frac{z x \eta \alpha(\alpha-1) n^{\prime \alpha-2}}{1-\eta(1-\alpha)}
$$


Now, compute the right hand side of equation (39) to verify that the guess is actually a right one.

$$
\begin{aligned}
& (1-\eta) b+\eta\left[z x \alpha n^{\prime \alpha-1}-w_{n}\left(z, x, d, m^{\prime}, n^{\prime}\right) n^{\prime}\right. \\
& \left.+\tau\left(1-\beta+\beta \int d^{\prime} d G_{d}\left(d^{\prime} \mid d\right)\right)+\beta \int f\left(z^{\prime}, m^{\prime}\right)\left(\tau+\frac{\kappa}{q\left(z^{\prime}, m^{\prime}\right)}\right) d G_{z}\left(z^{\prime} \mid z\right)\right] \\
& =(1-\eta) b+\eta\left[z x \alpha n^{\prime \alpha-1}-\frac{z x \eta \alpha(\alpha-1) n^{\prime \alpha-1}}{1-\eta(1-\alpha)}\right. \\
& \left.+\tau\left(1-\beta+\beta \int d^{\prime} d G_{d}\left(d^{\prime} \mid d\right)\right)+\beta \int f\left(z^{\prime}, m^{\prime}\right)\left(\tau+\frac{\kappa}{q\left(z^{\prime}, m^{\prime}\right)}\right) d G_{z}\left(z^{\prime} \mid z\right)\right] \\
& =(1-\eta) b+\eta\left[\frac{z x \alpha n^{\prime \alpha-1}}{1-\eta(1-\alpha)}+\tau\left(1-\beta+\beta \int d^{\prime} d G_{d}\left(d^{\prime} \mid d\right)\right)\right. \\
& \left.+\beta \int f\left(z^{\prime}, m^{\prime}\right)\left(\tau+\frac{\kappa}{q\left(z^{\prime}, m^{\prime}\right)}\right) d G_{z}\left(z^{\prime} \mid z\right)\right] \\
& =w\left(z, x, d, m^{\prime}, n^{\prime}\right)
\end{aligned}
$$

This verifies the guess.

\section{A.3 Details of the Computational Algorithm}

We solve the model numerically. In particular, our solution method relies on the partial information approach developed by Krusell and Smith (1998). ${ }^{28}$ Notice that one of the aggregate state variables is $m$, the type distribution of heterogeneous firms. This is a very large object and it is virtually impossible to store in a computer. Moreover, we need to deal with $\Phi_{m}(z, m)$ which maps the space of type distribution and the space of aggregate productivity shock into the space of type distribution. Naturally, an important element of the solution method is how to deal with the large state variable. This is where the method by Krusell and Smith (1998) helps. The essence of the approach is to limit the information that agents in the model use to a finite set of statistics summarizing the type distribution, which is the original state variable. Effectively, the approach is implemented by replacing the large state variable by a finite set (desirably very small number) of statistics that summarize the type distribution.

We use $N$, the total number of jobs (employment) as the set of statistics to summarize and replace $m$, since this is the minimum set of the state variables that effectively replaces $m$. The approximate equilibrium can be constructed by replacing $m$ by $N$ in the model. After

\footnotetext{
${ }^{28}$ We also exploit the extension developed by Krusell and Smith (1997). Ríos-Rull (1999) offers a good summary of the methods.
} 
solving the approximate equilibrium with $N$, we can evaluate whether $N$ is sufficient to make the approximate equilibrium close to the true equilibrium by adding one more statistics and see how the model properties change. If the model properties are not significantly affected by the addition, we can safely assume that the approximate equilibrium with $N$ is close to the true equilibrium which is associated with full information $(m)$.

Accordingly, the functions for the aggregate employment in the next period $\Phi_{m}(z, m)$, and the number of vacancies posted $\Phi_{V}(z, m)$ are replaced by $\Phi_{N}(z, N)$ and $\Phi_{V}(z, N)$, respectively.

We solve the optimal decision of firms for grid points placed on the space of $n$ and $N$. The bounds of $n$ are chosen such that the optimal decision for $n^{\prime}$ stays within the bounds. The bounds of $N$ are chosen such that the bounds do not bind in simulations.

Logarithm of both aggregate and idiosyncratic shocks are assumed to follow AR(1) process. As for the idiosyncratic productivity shock $x$, we use the approximation method proposed by Ada and Cooper (2003), which is an extension of the method developed by Tauchen (1986), to approximate the original AR(1) process with a finite-state first order Markov process. With the method of Ada and Cooper (2003), the abscissas are automatically chosen. We denote $p_{x x^{\prime}}$ as the Markov transition probabilities for $\log x$.

As for the aggregate productivity shock $z$, we keep the original AR(1) process, but approximate the original $\mathrm{AR}(1)$ process with a finite-state first order Markov process when taking expectations to compute the optimal decision rule. In particular, we use Tauchen (1986) to approximate the $\mathrm{AR}(1)$ process. The abscissas are equally-spaced and end points are chosen such that, when we simulate the model using the original $\mathrm{AR}(1)$ process, realization of $\log z$ does not go out of the interval bracketed by the two end points. Optimal decision rules are solved for abscissas placed on the space of $\log z$, and we use piecewise linear approximation to compute the optimal decision off the abscissas with respect to $\log z$. We denote $p_{z z^{\prime}}$ as the Markov transition probabilities for $\log z$.

We approximate the type distribution of heterogeneous firms using sampling. We create $I$ firms and run simulations with $I$ firms. Since we assume that the total measure of firms is one, each firm in the sample carries the weight of $\frac{1}{I}$. The type of a firm $i$ in period $t$ is represented by a triplet $\left(x_{i, t}, d_{i, t}, n_{i, t}\right)$. Total employment $N$, and total number of job seekers $S$ in period $t$ can be computed by:

$$
\begin{aligned}
& N_{t}=\frac{1}{I} \sum_{i=1}^{I} n_{i, t} \\
& S_{t}=L-N_{t}
\end{aligned}
$$


respectively. We can compute the realized number of vacancies posted in period $t$ as follows:

$$
\widetilde{V}_{t}=\frac{1}{f\left(z_{t}, N_{t}\right)} \frac{1}{I} \sum_{i=1}^{I} \max \left(\phi_{n}\left(z_{t}, x_{i, t}, d_{i, t}, N_{t}, n_{i, t}\right)-\left(1-d_{i, t}\right) n_{i, t}, 0\right)
$$

Now we are ready to state the detailed solution algorithm.

\section{Algorithm 1 (Computation Algorithm of the Approximate Equilibrium)}

1. Parameterize the forecasting functions $\Phi_{N}(z, N)$ and $\Phi_{V}(z, N)$. We assume a simple loglinear functional form as follows:

$$
\begin{aligned}
& \log N^{\prime}=\Phi_{N}(z, N)=\Phi_{N, 0}+\Phi_{N, 1} \log Z+\Phi_{N, 2} \log N \\
& \log V=\Phi_{V}(z, N)=\Phi_{V, 0}+\Phi_{V, 1} \log Z+\Phi_{V, 2} \log N
\end{aligned}
$$

2. Set an initial guess of the coefficients $\left\{\Phi_{N, 0}, \Phi_{N, 1}, \Phi_{N, 2}, \Phi_{V, 0}, \Phi_{V, 1}, \Phi_{V, 2}\right\}$. Denote the initial guess of the set of coefficients as $\Phi^{0}$.

3. Set a guess of the expected marginal value function $D^{0}\left(z, x, d, N^{\prime}, n^{\prime}\right)$.

4. Use the following first order conditions to obtain two thresholds $\bar{n}^{*}(z, x, d, N)$ and $\underline{n}^{*}(z, x, d, N)$ which characterize the optimal decision rule $n^{\prime}=\phi_{n}(z, x, d, N, n)$.

$$
\begin{array}{r}
z x F^{\prime}\left(\bar{n}^{*}\right)-w\left(z, x, d, N^{\prime}, \bar{n}^{*}\right)-w_{n}\left(z, x, d, N^{\prime}, \bar{n}^{*}\right) \bar{n}^{*}+\tau+\beta D^{0}\left(z, x, d, N^{\prime}, \bar{n}^{*}\right)=0 \\
z x F^{\prime}\left(\underline{n}^{*}\right)-w\left(z, x, d, N^{\prime}, \underline{n}^{*}\right)-w_{n}\left(z, x, d, N^{\prime}, \underline{n}^{*}\right) \underline{n}^{*}-\frac{\kappa}{q(z, N)}+\beta D^{0}\left(z, x, d, N^{\prime}, \underline{n}^{*}\right)=0
\end{array}
$$

where $N^{\prime}=\exp \Phi_{N}^{0}(z, N)$ and $V=\exp \Phi_{V}^{0}(z, N)$.

5. Update $D^{0}\left(z, x, d, N^{\prime}, n^{\prime}\right)$ and obtain $D^{1}\left(z, x, d, N^{\prime}, n^{\prime}\right)$ using the following Bellman operator:

$$
D^{1}\left(z, x, d, N^{\prime}, n^{\prime}\right)=\sum_{z^{\prime}} \sum_{x^{\prime}} \sum_{d^{\prime}} p_{z z^{\prime}} p_{x x^{\prime}} p_{d d^{\prime}} \Pi_{n}\left(z^{\prime}, x^{\prime}, d^{\prime}, N^{\prime}, n^{\prime}\right)
$$

where

$$
\begin{aligned}
& \Pi_{n}\left(z^{\prime}, x^{\prime}, d^{\prime}, N^{\prime}, n^{\prime}\right)=\left(1-d^{\prime}\right) \\
& \begin{cases}-\tau & \text { if } \widetilde{n}^{\prime}>\bar{n}^{*} \\
z^{\prime} x^{\prime} F^{\prime}\left(\widetilde{n}^{\prime}\right)-w\left(z^{\prime}, x^{\prime}, d^{\prime}, N^{\prime \prime}, \widetilde{n}^{\prime}\right)-w_{n}\left(z^{\prime}, x^{\prime}, d^{\prime}, N^{\prime \prime}, \widetilde{n}^{\prime}\right) \widetilde{n}^{\prime}+\beta D^{0}\left(z^{\prime}, x^{\prime}, d^{\prime}, N^{\prime \prime}, \widetilde{n}^{\prime}\right) & \text { if } \widetilde{n}^{\prime} \in\left[\underline{n}^{*}, \bar{n}^{*}\right] \\
\frac{\kappa}{q\left(z^{\prime}, m^{\prime}\right)} & \text { if } \widetilde{n}^{\prime}<\underline{n}^{*}\end{cases}
\end{aligned}
$$


and $N^{\prime \prime}=\exp \Phi_{N}\left(z^{\prime}, N^{\prime}\right), \widetilde{n}^{\prime}=\left(1-d^{\prime}\right) n^{\prime}, V^{\prime}=\exp \Phi_{V}\left(z^{\prime}, N^{\prime}\right)$, and $\bar{n}^{*}$ and $\underline{n}^{*}$ are characterized by equations (47), (48), respectively, for $\left(z^{\prime}, x^{\prime}, d^{\prime}, N^{\prime \prime}\right)$.

6. Compare $D^{0}\left(z, x, d, N^{\prime}, n^{\prime}\right)$ and $D^{1}\left(z, x, d, N^{\prime}, n^{\prime}\right)$. If the chosen norm is smaller than a predetermined tolerance level, stop the iteration and go to the next step. Otherwise, update $D^{0}\left(z, x, d, N^{\prime}, n^{\prime}\right)$ by replacing it by $D^{1}\left(z, x, d, N^{\prime}, n^{\prime}\right)$ and go back to step 4 .

7. We will simulate the model economy to update $\Phi^{0}$. First, set the length of simulation T. Draw a sequence of $\left\{z_{t}\right\}_{t=1}^{T}$ using a random number generator. Set the initial type distribution of firms $\left\{\left(x_{i, 1}, d_{i, 1}, n_{i, 1}\right)\right\}_{i=1}^{I}$. We choose the steady state type distribution as the initial distribution.

8. In period $t$, using the current type distribution, we can compute the current $N_{t}$ and $S_{t}$.

9. Start finding a consistent $V_{t}$. First, set $V_{t}^{0}=\exp \Phi_{V}\left(z_{t}, N_{t}\right)$.

10. Using $V_{t}^{0}$, solve the optimal decision of firms. Using the optimal decision and the type distribution in the current period, compute the realized $\widetilde{V}_{t}^{0}$.

11. Compare $V_{t}^{0}$ and $\widetilde{V}_{t}^{0}$. if they are closer than a predetermined tolerance level, take $V_{t}^{0}$ as $V_{t}$ and go to the next step. otherwise, update $V_{t}^{0}$, by taking the weighted average of $V_{t}^{0}$ and $\widetilde{V}_{t}^{0}$ and go back to step 10 .

12. Update the type distribution using the optimal decision rule $\phi_{n}(z, x, d, N, n)$ associated with the consistent $V_{t}$.

13. If this is the last period of simulation. Stop and go to the next step. otherwise, go back to step 8 with the updated distribution and $z$ in the next period.

14. Now we have the time series of $\left\{N_{t}\right\}_{t=1}^{T}$ and $\left\{V_{t}\right\}_{t=1}^{T}$. Drop the first $T^{0}$ periods to eliminate the effect from the choice of the initial conditions. Use OLS regression for (45) and (46) and obtain coefficients $\Phi^{1}$ associated with the simulated time series.

15. Compare $\Phi^{0}$ and $\Phi^{1}$. if the distance is less than a predetermined tolerance level, stop and go to the next step. Otherwise, update $\Phi^{0}$ and go back to step 3.

16. If the coefficients do not converge, or fit of the regression is not good, it might be necessary to change the functional forms of $\Phi_{N}$ and $\Phi_{V}$ or increase the set of statistics to replace $m$. 
17. Once the consistent $\Phi_{N}, \Phi_{V}, w\left(z, x, d, N^{\prime}, n^{\prime}\right), D\left(z, x, d, N^{\prime}, n^{\prime}\right)$ and $\phi_{n}(z, x, d, N, n)$ are obtained, we can run simulations to study cyclical properties of the model.

\section{References}

Acemoglu, Daron and William Hawkins, "Equilibrium Unemployment in a Generalized Search Model," July 2006. Unpublished manuscript.

Ada, Jerome and Russel Cooper, Dynamic Economics, Cambridge, Massachusetts: MIT Press, 2003.

Andolfatto, David, "Business Cycles and Labor-Market Search," American Economic Review, March 1996, 86 (1), 112-132.

Barron, John, Mark Berger, and Dan Black, "Employer Search, Training, and Vacancy Duration," Economic Inquiry, 1997, 35 (1), 167-192.

Cahuc, Pierre and Etienne Wasmer, "Does intrafirm bargaining matter in the large firm's matching model?," Macroeconomic Dynamics, 2001, 5 (5), 742-747.

_, Francois Marque, and Etienne Wasmer, "A theory of wages and labor demand with intra-firm bargaining and matching frictions," International Economic Review, August 2008, $49(3), 943-972$.

Campbell, Jeffrey and Jonas Fisher, "Aggregate Employment with Microeconomic Asymmerties," American Economic Review, December 2000, 90 (5), 1323-1345.

Canova, Fabio, David Lopez-Salido, and Claudio Michelacci, "Shumpeterian Technology Shocks," October 2007. Unpublished manuscript.

Cole, Harold and Richard Rogerson, "Can the Mortensen-Pissarides Matching Model Match the Business-Cycle Facts?," International Economic Review, November 1999, 40 (4), 933-959.

Cooper, Russel, John Haltiwanger, and Jonathan Willis, "Search frictions: Matching aggregate and establishment observations," Journal of Monetary Economics, October 2007, 54 (S1), 56-78. 
Davis, Steven and John Haltiwanger, "On the Driving Forces Behind Cyclical Movements in Employment and Job Reallocation," American Economic Review, December 1999, 89 (5), $1234-1258$.

_ , Jason Faberman, John Haltiwanger, and Ian Rucker, "Adjusted Estimates of Worker Flows and Job Openinings in JOLTS," June 2008. NBER Working Paper No. 14137.

_ , John Haltiwanger, and Scott Schuh, Job Creation and Destruction, MIT Press, 1996.

Den Haan, Wouter, Garey Ramey, and Joel Watson, "Job Destruction and Propagation of Shocks," American Economic Review, June 2000, 90 (3), 482-98.

Elsby, Michael and Ryan Michaels, "Marginal Jobs, Heterogenous Firms, and Unemployment Flows," January 2008. Unpublished manuscript.

_ , _ , and Gary Solon, "The Ins and Outs of Cyclical Unemployment," American Economic Journal: Macroeconomics, January 2009, 1 (1), 84-110.

Éva Nagypál, "Reallocation over the Business Cycle: The Importance of Job-to-Job Transitions," March 2008. Unpublished manuscript.

Faberman, Jason, "Job Flows over the Recent Business Cycle: Not All 'Recoveries' are Created Equal," February 2006. Unpublished manuscript.

Fujita, Shigeru, "The Cyclicality of Worker Flows and Vacancies: Evidence from the Sign Restriction Approach," Journal of Applied Econometrics, forthcoming.

- and Garey Ramey, "The Cyclicality of Job Loss and Hiring," November 2006. Federal Reserve Bank of Philadelphia Working Paper 06-17.

_ and _, "Job Matching and Propagation," Journal of Economic Dynamics and Control, November 2007, 31, 3671-3698.

_ and _ , "The Cyclicality of the Separation and Job Finding Rates," International Economic Review, May 2009, 50 (2), 415-430.

Hagedorn, Marcus and Iourii Manovskii, "The Cyclical Behavior of Equilibrium Unemployment and Vacancies Revisited," American Economic Review, September 2008, 98 (4), 1962-1706. 
Hall, Robert, "Employment Efficiency and Sticky Wages: Evidence from Flows in the Labor Market," Review of Economics and Statistics, August 2005, 87 (3), 397-407.

Hopenhayn, Hugo and Richard Rogerson, "Job Turnover and Policy Evaluation: A General Equilibrium Analysis," Journal of Political Economy, 1993, 101 (5), 915-938.

Krause, Michael and Thomas Lubik, "Does intra-firm bargaining matter for business cycle dynamics?," 2007. Deutsche Bundesbank Discussion Paper No. 17/2007.

Krusell, Per and Anthony Smith, "Income and Wealth Heterogeneity, Portfolio Choice, and Equilibrium Asset Returns," Macroeconomic Dynamics, 1997, 1 (2), 387-422.

_ and _, "Income and Wealth Heterogeneity in the Macroeconomy," Journal of Political Economy, 1998, 106, 867-896.

Merz, Monika, "Search in the Labor Market and the Real Business Cycle," Journal of Monetary Economics, 1995, 36, 269-300.

Mortensen, Dale and Christopher Pissarides, "Job Creation and Job Destruction in the Theory of Unemployment," Review of Economic Studies, 1994, 61, 397-415.

_ and Éva Nagypál, "More on Unemployment and Vacancy Fluctuations," Review of Economic Dynamics, 2007, 10 (3), 327-347.

Petrongolo, Barbara and Christopher Pissarides, "Looking Into the Black Box: A Survey of the Matching Function," Journal of Economic Literature, June 2001, 39, 390-431.

Ramey, Garey, "Exogenous vs. Endogenous Separation," October 2008. Unpublished manuscript.

Ríos-Rull, José-Víctor, "Computation of Equilibria in Heterogeneous-Agent Models," in Ramon Marimon and Scott Andrew, eds., Computational Methods for the Study of Economic Dynamics, Oxford: Oxford University Press, 1999, chapter 11.

Rotemberg, Julio, "Cyclical Wages in a Search-and-Bargaining Model with Large Firms," July 2006. Unpublished manuscript.

Shimer, Robert, "The Cyclical Behavior of Equilibrium Unemployment and Vacancies," American Economic Review, March 2005, 95 (1), 25-49. 
_ , "Reassessing the Ins and Outs of Unemployment," November 2007. Unpublished manuscript.

Smith, Eric, "Search, Concave Production, and Optimal Firm Size," Review of Economic Dynamics, April 1999, 2 (2), 456-471.

Stole, Lars and Jeffrey Zwiebel, "Intra-firm Bargaining under Non-binding Contracts," Review of Economic Studies, July 1996, 63 (3), 375-410.

_ and _ , "Organizational Design and Technology Choice under Intrafirm Bargaining," American Economic Review, March 1996, 86 (1), 195-222.

Tasci, Murat, "On-the-job search and labor market reallocation," December 2007. Federal Reserve Bank of Cleveland Working Paper 07-25.

Tauchen, George, "Finite State Markov-Chain Approximations to Univariate and Vector Autoregressions," Economics Letters, 1986, 20 (2), 177-181.

Veracierto, Marcelo, "Firing Costs and Business Cycle Fluctuations," International Economic Review, February 2008, 49 (1), 1-39.

Yashiv, Eran, "Evaluating the performance of the search and matching model," European Economic Review, May 2006, 50 (4), 909-936.

_ , "U.S. Labor Market Dynamics Revisited," Scandinavian Journal of Economics, December 2007, 109 (4), 779-806. 